\title{
A NOVEL APPROACH TO MINERAL CARBONATION: ENHANCING CARBONATION WHILE AVOIDING MINERAL PRETREATMENT PROCESS COST
}

Type of Report: $\quad$ Annual

Reporting Period Start Date: June 22, 2004

Reporting Period End Date: June 21, 2005

Principal Authors: $\quad$ Michael J. McKelvy, ${ }^{*}$ Andrew V.G. Chizmeshya, Kyle Squires, Ray W. Carpenter, and Hamdallah Béarat.

Date Report Issued: $\quad$ October 2005

DOE Award Number: $\quad$ DE-FG26-04NT42124

Submitting Organization: Arizona State University Center for Solid State Science, Science and Engineering of Materials Graduate Program, and Department of Mechanical and Aerospace Engineering Tempe, AZ 85287-1704

* Phone: (480) 965-4535; FAX: (480) 965-9004;

E-mail: mckelvy@asu.edu 


\section{DISCLAIMER}

This report is prepared as an account of work sponsored by an agency of the United States Government. Neither the United States Government nor any agency thereof, nor any of their employees, makes any warranty, express or implied, or assumes any legal liability or responsibility for the accuracy, completeness, or usefulness of any information, apparatus, product, or process disclosed, or represents that its use would not infringe privately owned rights. Reference herein to any specific commercial product, process, or service by trade name, trademark, manufacturer, or otherwise does not necessarily constitute or imply its endorsement, recommendation, or favoring by the United States Government or any agency thereof. The views and opinions of authors expressed herein do not necessarily state or reflect those of the United States Government or any agency thereof. 


\begin{abstract}
Known fossil fuel reserves, especially coal, can support global energy demands for centuries to come, if the environmental problems associated with $\mathrm{CO}_{2}$ emissions can be overcome. Unlike other $\mathrm{CO}_{2}$ sequestration candidate technologies that propose long-term storage, mineral sequestration provides permanent disposal by forming geologically stable mineral carbonates. Carbonation of the widely occurring mineral olivine (e.g., forsterite, $\mathrm{Mg}_{2} \mathrm{SiO}_{4}$ ) is a large-scale sequestration process candidate for regional implementation, which converts $\mathrm{CO}_{2}$ into the environmentally benign mineral magnesite $\left(\mathrm{MgCO}_{3}\right)$. The primary goal is cost-competitive process development. As the process is exothermic, it inherently offers low-cost potential. Enhancing carbonation reactivity is key to economic viability. Recent studies at the U.S. DOE Albany Research Center have established that aqueous-solution carbonation using supercritical $\mathrm{CO}_{2}$ is a promising process; even without olivine activation, 30-50\% carbonation has been achieved in an hour. Mechanical activation (e.g., attrition) has accelerated the carbonation process to an industrial timescale (i.e., near completion in less than an hour), at reduced pressure and temperature. However, the activation cost is too high to be economical and lower cost pretreatment options are needed. Herein, we report our first year progress in exploring a novel approach that offers the potential to substantially enhance carbonation reactivity while bypassing pretreatment activation.
\end{abstract}

We have discovered that robust silica-rich passivating layers form on the olivine surface during carbonation. As carbonation proceeds, these passivating layers thicken, fracture and eventually exfoliate, exposing fresh olivine surfaces during rapidly-stirred/circulating carbonation. We are exploring the mechanisms that govern carbonation reactivity and the impact that (i) modeling/controlling the slurry fluid-flow conditions, (ii) varying the aqueous ion species/size and concentration (e.g., $\mathrm{Li}^{+}, \mathrm{Na}^{+}, \mathrm{K}^{+}, \mathrm{Rb}^{+}, \mathrm{Cl}^{-}, \mathrm{HCO}_{3}{ }^{-}$), and (iii) incorporating select sonication offer to enhance exfoliation and carbonation. Thus far, we have succeeded in nearly doubling the extent of carbonation observed compared with the optimum procedure previously developed by the Albany Research Center. Aqueous carbonation reactivity was found to be a strong function of the ionic species present and their aqueous activities, as well as the slurry fluid flow conditions incorporated. Synergistic control of these parameters offers the potential for further improvements in carbonation reactivity. A new sonication exfoliation system incorporating a novel sealing system was developed to carry out the sonication studies. Our initial studies that incorporate controlled sonication have not yet lead to a significant improvement in the extent of carbonation observed. Year 2 studies will emphasize those approaches that offer the greatest potential to cost effectively enhance carbonation, as well as combined approaches that may further enhance carbonation.

Mechanistic investigations indicate incongruent dissolution results in the observed silica-rich passivating layer formation. Observations of magnesite nanocrystals within the passivating layers that form indicate the layers can exhibit significant permeability to the key reactants present (e.g., $\mathrm{Mg}^{2+}, \mathrm{H}^{+}, \mathrm{H}_{2} \mathrm{O}, \mathrm{CO}_{2}$, and $\mathrm{HCO}_{3}{ }^{-}$). Atomistic modeling supports the observation of robust passivating layers that retain significant permeability to the key reaction species involved. Studies in Year 2 will emphasize the impact that controlled aqueous speciation and activity and slurry-flow dynamics have on the mechanisms that control carbonation reactivity and the potential they offer to substantially reduce olivine mineral sequestration process cost. 


\section{TABLE OF CONTENTS}

Title Page

Disclaimer

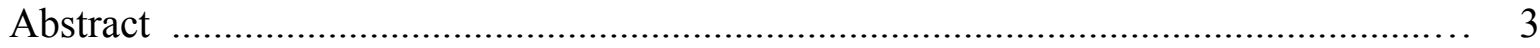

Table of Contents

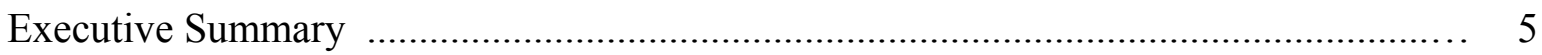

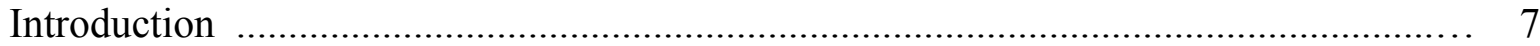

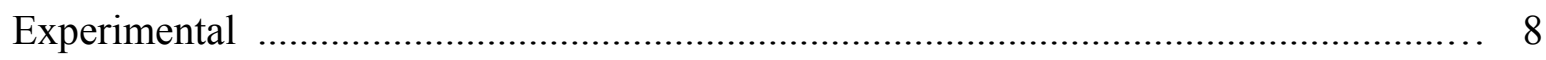

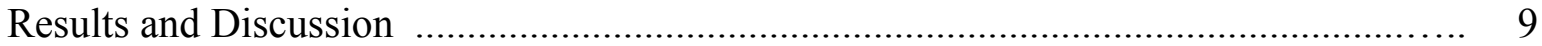

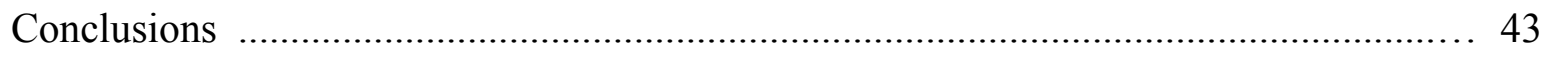

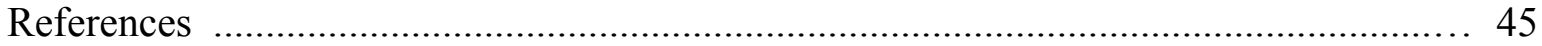




\section{EXECUTIVE SUMMARY}

$\mathrm{CO}_{2}$ mineral sequestration provides permanent disposal by forming geologically stable and environmentally benign mineral carbonates. Carbonation of olivine (e.g., forsterite, $\mathrm{Mg}_{2} \mathrm{SiO}_{4}$ ) is a large-scale sequestration process candidate for regional implementation. Cost-effectively enhancing carbonation reactivity is central to economically viable process development. Aqueous-solution carbonation shows particular promise. However, the associated mineral activation cost currently needed to suitably enhance carbonation is too high. Lower cost pretreatment options are needed. In the first year of this two-year project, we have begun to explore the potential to substantially enhance carbonation reactivity via a novel approach that bypasses pretreatment activation altogether.

Silica-rich passivating layers were discovered to form on the olivine surface during carbonation. As carbonation proceeds, the layers thicken, fracture and exfoliate during rapidlystirred/circulating carbonation, exposing fresh olivine and enhancing carbonation. Three approaches to cost-effectively enhance carbonation, while avoiding the cost of olivine pretreatment activation, are being explored: (i) controlling the aqueous chemistry (e.g., $\mathrm{Li}^{+}, \mathrm{Na}^{+}$, $\mathrm{K}^{+}, \mathrm{Rb}^{+}, \mathrm{Cl}^{-}$, and $\mathrm{HCO}_{3}{ }^{-}$activities), (ii) integration of slurry flow modeling with experiment, and (iii) incorporating select sonication. The goal is explore the potential to mitigate the effectiveness of passivating layer formation, enhancing exfoliation and carbonation. During the first project year we succeeded in nearly doubling the extent of carbonation compared with that observed for the optimum procedure previously developed by the Albany Research Center (ARC).

Carbonation reactivity was discovered to be a very complicated function of the aqueous solution species and their activities. Studies varying the aqueous alkali cation species present in the optimum solution developed by the $\mathrm{ARC}\left(0.64 \mathrm{M} \mathrm{NaHCO}_{3}+1.00 \mathrm{M} \mathrm{NaCl}\right)$ were undertaken to selectively compare cation effectiveness in enhancing carbonation/exfoliation. The alkali cation species present and their ratio were found to dramatically impact carbonation reactivity, with extent of carbonation varying by a factor of 20 from the least to the most effective alkali cation combination. The most promising solutions for enhancing carbonation to date have provided substantial increases in extent of carbonation, nearly doubling it. High concentrations of $\mathrm{NaHCO}_{3}(2.5 \mathrm{M})$ and $\mathrm{KHCO}_{3}(5.5 \mathrm{M})$ were found to be particularly effective at enhancing carbonation, with the extent of carbonation again exhibiting a strong dependence on the alkali cation species present. In contrast, the alkali chloride solutions studied to date have exhibited poor carbonation reactivity by themselves, but can substantially enhance carbonation reactivity in combination with alkali bicarbonate under select conditions. $\mathrm{CO}_{2}(\mathrm{aq})$ and $\mathrm{HCO}_{3}{ }^{-}$play key synergistic roles in enhancing carbonation, as carbonation drops off dramatically in the presence of $\mathrm{HCO}_{3}^{-}(\mathrm{aq})$ or $\mathrm{CO}_{2}(\mathrm{aq})$ alone.

Multi-phase fluid modeling and experimental investigations were initiated to elucidate important slurry-flow parameters that enhance exfoliation and carbonation (e.g., via particle-particle and particle-wall collisions). A new microscopic wall roughness model was developed and extensively validated. Subsequent computational investigations were found to indicate wall roughness can strongly enhance cross-stream transport, particle-particle collisions and carbonation. The Fluent code was validated for application to multiphase flows to assess the 
complex effects governing flow. Calculation of whole systems, such as the flow loop reactor at the ARC, remains a substantial challenge. However, initial results for system components have revealed the radial distribution of flow in a component pipe can be a strong function of particle mass/size distribution and mixing history. As particle mass was found to be an important factor in cross-stream particle transport, we initiated a series of studies to explore the effect of particle mass/size distribution on exfoliation and carbonation in collaboration with the ARC using the ARC flow loop reactor and the ASU batch reactor. Initial results demonstrate that the flow dynamics and particle mass/size distribution present can substantially impact exfoliation/carbonation.

A controlled pressure and temperature $20 \mathrm{kHz}$ sonication system was successfully developed for these studies. The system is based on a Sonics 1500 watt power supply and a special probe to adapt to our custom controlled pressure (1 to $200 \mathrm{~atm})$ and temperature $\left(20\right.$ to $250{ }^{\circ} \mathrm{C}$ ) sonication vessel. System development required substantial R \& D to provide an effective sealing system between the sonic probe and the controlled pressure and temperature system. The sealing system was initially arranged to be designed and developed industrially. However, the required time table was not met by the vendor, necessitating in-house design and development, significantly delaying initial system deployment (months). The system is fully operational over the complete range of carbonation reaction conditions of interest. The effects of temperature and pressure on the effectiveness of sonication in enhancing carbonation have been explored. These studies will be expanded in Year 2, together with investigations of the effect of sonication power and time, fluid composition, and reactant particle concentration and size, as well as the effect of combining the most effective parameters observed. Parameters that have been found to be individually effective at cost-effectively enhancing carbonation reactivity (e.g., controlled fluid flow conditions and aqueous chemistry) will be combined to probe the potential to synergistically stimulate exfoliation and enhance carbonation.

Mechanistic investigations have extended fundamental understanding of the passivating layer formation process during the first project year. Incongruent dissolution generally results in silica-rich passivating layer (PL) formation, with silica dissolution-precipitation likely further contributing to PL growth. Observations of magnesite nanocrystals within the passivating layers that form indicate the layers exhibit significant permeability to the key reactants present (e.g., $\mathrm{Mg}^{2+}, \mathrm{H}^{+}, \mathrm{H}_{2} \mathrm{O}, \mathrm{CO}_{2}$, and $\mathrm{HCO}_{3}{ }^{-}$). Carbonation increases dramatically with increasing weight \% solids in stirred experiments, indicating particle-particle collisions are critical in enhancing exfoliation and carbonation. Addition of abrasive materials, such as quartz, can significantly enhance olivine carbonation, in further support of the importance of particle-particle collisions in exfoliation and carbonation processes. Multi-phase hydrodynamic calculations indicate secondary collisions can account for a large fraction of the abrasion/exfoliation observed. Largescale atomic-level simulations of the reaction zone are consistent with a PL that possesses a "glassy" but highly defective $\mathrm{SiO}_{2}$ structure that can permit the diffusion of key reactants during carbonation. Studies in Year 2 will emphasize the impact that controlled aqueous speciation, activity and slurry-flow dynamics have on the mechanisms that control carbonation reactivity, as they appear to offer the greatest potential to substantially reduce olivine mineral sequestration process cost. 


\section{INTRODUCTION}

Coal, in particular, and fossil fuels, in general, are well positioned to supply the world's energy needs for centuries to come if carbon sequestration technology can be developed that is (i) permanent, (ii) environmentally benign, and (iii) economically viable. ${ }^{1} \mathrm{CO}_{2}$ mineral sequestration provides permanent disposal, by forming geologically stable mineral carbonates. ${ }^{2-5}$ The materials produced are also environmentally benign and found in vast quantities in nature. The primary challenge is economically viable process development. As permanent disposal inherently avoids the ongoing monitoring, remediation and liability costs associated with longterm storage, the key is reducing mineral sequestration process cost. Cost effectively enhancing carbonation reactivity is critical. Enhancing mineral carbonation during geological (belowground) sequestration is highly desirable as well, as it can similarly ensure long-term sequestration stability via the formation of thermodynamically stable mineral carbonates. ${ }^{6}$ Investigating and evaluating candidate technologies that incorporate mineral sequestration (above and below ground) is the primary focus of the $\mathrm{CO}_{2}$ Mineral Sequestration Working Group, which is managed by DOE (Fossil Energy), and consists of members from the Albany Research Center, Argonne National Laboratory, Arizona State University, Los Alamos National Laboratory, and the National Energy Technology Laboratory.

Carbonation of $\mathrm{Mg}$-rich olivine minerals (e.g., forsterite, $\mathrm{Mg}_{2} \mathrm{SiO}_{4}$ ) is a leading mineral sequestration process candidate. ${ }^{7,8}$ These minerals are available worldwide in quantities sufficient to support the regional implementation of above-ground mineral sequestration. ${ }^{8}$ Their low-cost $(\sim 4-5 / \text { ton for mined and milled feedstock })^{7,8}$ and exothermic carbonation (reaction 1) (8), provide the potential for economically viable process development.

$$
1 / 2 \mathrm{Mg}_{2} \mathrm{SiO}_{4}+\mathrm{CO}_{2} \rightarrow \mathrm{MgCO}_{3}+1 / 2 \mathrm{SiO}_{2}+88 \mathrm{~kJ} / \mathrm{mol}
$$

Recent studies at the Albany Research Center indicate aqueous solution carbonation is a promising approach. ${ }^{7,8}$ Even without special activation, 30-50\% carbonation has been achieved in an hour for $<37$ micron olivine reacted at $185{ }^{\circ} \mathrm{C}$ and 150 bar $\mathrm{CO}_{2}$. Mechanical pretreatment via intense attrition accelerates carbonation to near completion in less than an hour and at reduced pressures and temperatures. However, the activation cost is too high for cost-effective sequestration. $^{8}$

Economically viable process development will require novel approaches that enhance mineral carbonation reactivity, while bypassing costly mineral pretreatment. The potential to develop low-cost chemical pretreatment processes has been explored for years, but success remains elusive. ${ }^{6}$ Enhancing carbonation, while avoiding the expense of olivine pretreatment, would substantially reduce process cost and provide a significant advance. We recently discovered that aqueous olivine mineral carbonation is associated with robust passivating layer formation, which substantially inhibits mineral carbonation. Herein, we are exploring novel low-cost approaches with the potential to facilitate passivating layer exfoliation to enhance carbonation and develop an atomic level understanding of the associated mechanisms. The goal is to develop the understanding needed to engineer new low-cost carbonation processes that avoid the cost of pretreatment activation. The primary focus is on enhancing passivating layer exfoliation, which 
has the potential to substantially enhance carbonation without the need for pretreatment activation.

\section{EXPERIMENTAL}

Single crystal olivine fragments from San Carlos, Arizona, were used to explore the effects of aqueous solution chemistry, particle size and sonication on olivine carbonation reactivity, as well as the mechanisms that govern passivating layer formation and exfoliation processes. The elemental composition was determined to be $\left(\mathrm{Mg}_{0.915} \mathrm{Fe}_{0.085}\right)_{2} \mathrm{SiO}_{4}$ by electron microprobe and particle induced X-ray emission analysis. X-ray diffraction (XRD) of powdered samples showed the lattice constants are in good agreement with those observed for olivine containing $\sim 8 \% \mathrm{Fe}$ $(\mathrm{a}=4.763 \AA, \mathrm{b}=10.223 \AA, \mathrm{c}=5.993 \AA){ }^{9,10}$ Trace impurities observed were well below $1 \%$, with $\mathrm{Ca}$ being the principle trace impurity. Single crystals and single crystal fragments were used to facilitate microscopic observation of passivating layer formation/exfoliation and the reaction surfaces and interfaces that form during carbonation. Synthetic forsterite $\left(\mathrm{Mg}_{2} \mathrm{SiO}_{4}\right)(99 \%$ $\mathrm{Mg}_{2} \mathrm{SiO}_{4}$; Alfa Aesar) was used for select carbonation investigations. Twin Sisters olivine was used for the flow-loop reactor studies carried out in collaboration with the Albany Research Center. ${ }^{7}$ The flow-loop reactor has been previously described. ${ }^{8}$ All of the olivine size fractions investigated herein ( $<37$ micron, 37-75 micron, $<75$ micron, 75-150 micron and $<150$ micron) were wet screened. The extent of carbonation observed is compared with the optimum process to date for enhancing carbonation developed by the Albany Research Center (ARC), ${ }^{7,8}$ which is summarized below for forsterite carbonation.

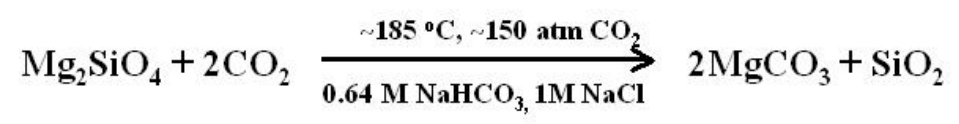

Reactions were carried out using a variety of aqueous species (e.g., $\mathrm{Li}^{+}, \mathrm{Na}^{+}, \mathrm{K}^{+}, \mathrm{Rb}^{+}, \mathrm{Cl}^{-}$, $\mathrm{HCO}_{3}{ }^{-}$) and species activities, particle size ranges and reaction times to probe their effect on carbonation and passivating layer formation/exfoliation. 1,500 rpm stirring was used to replicate the ARC process in the studies at Arizona State University. These mineral carbonation reactions were performed using a 100ml Autoclave Engineers EZE-Seal Hastelloy C-276 reactor, which is a smaller scale version of the 2,000 ml EZE-Seal Hastelloy C-276 reactor used at the Albany Research Center. Unstirred (static) experiments were undertaken to explore passivating layer formation in the absence of particle abrasion. San Carlos olivine single crystals $(\sim 1 \mathrm{x} 1 \mathrm{x} 0.1 \mathrm{~cm})$ with well-defined initial surface morphologies were incorporated to follow the reaction interface that forms down to the atomic level.

The extent of carbonation and hydrogen content of the product materials were assessed using a Perkin Elmer Series II CHNS Elemental Analyzer. Comparative standards gave total carbon and hydrogen accuracies of $\pm 0.3 \mathrm{wt} \%$. Extent of carbonation observations were compared with XRD intensity analysis of the product materials and found to be in good agreement. Select reaction products were analyzed structurally, morphologically, and analytically versus their extent of reaction to probe the mechanisms that govern carbonation.

XRD patterns were obtained using a Rigaku D/MAX-IIB X-ray diffractometer with $\mathrm{CuK} \alpha$ radiation. Scans were taken over different $2 \theta$ ranges between $10^{\circ}$ to $70^{\circ}$, with $0.01^{\circ} / \mathrm{s} \mathrm{steps}$. 
Reaction products were imaged using a Hitachi S-4700 field-emission scanning electron microscope (FESEM) or a FEI XL-30 Environmental FESEM. Elemental analysis of individual product particles was accomplished via energy dispersive X-ray spectroscopy (EDS). Crosssectioned samples of reaction interfaces were analyzed via FESEM and EDS mapping and highresolution transmission electron microscopy (HRTEM) using a JEOL 2010 with EDS and electron energy loss spectroscopy (EELS) capabilities.

Controlled pressure and temperature studies of the impact of sonication on olivine exfoliation/carbonation were carried out using our batch mineral carbonation reaction system described above and our specially developed controlled pressure and temperature sonication system described below. Sonication/carbonation studies have been carried out in stages. Hourlong carbonation studies are separated into three stages: (1) a half hour long run in the batch reactor, followed by (2) controlled sonication in the sonication system (e.g., one minute) and (3) a second half hour in the batch reactor. The above sonication runs are compared to both the standard one-hour carbonation runs using the batch reactor and runs that incorporate the sonication reaction stages ( $1 / 2$ hour plus $1 / 2$ hour batch reaction format), but without sonication.

\section{RESULTS AND DISCUSSION}

\section{Technical Accomplishments: Development of a Sonic Exfoliation System}

A controlled pressure and temperature $20 \mathrm{kHz}$ sonication system was successfully developed for these studies. The system is based on a Sonics 1500 watt power supply and a special probe to adapt to our custom controlled pressure (1 to $200 \mathrm{~atm})$ and temperature $\left(20\right.$ to $250{ }^{\circ} \mathrm{C}$ ) sonication vessel. The pressure and temperature control system used is the same system used to conduct our aqueous carbonation reactions. The impeller driven stirring system is replaced by the sonic probe. Other than the interchangeable sonication and impeller components, the remainder of the system remains essentially the same.

System development required substantial R \& D to provide an effective sealing system between the sonic probe and the controlled pressure and temperature system. The sealing system was initially arranged to be designed and developed industrially. However, the required time table was not met, necessitating in-house design and development, delaying initial system deployment for months. The system is fully operational. Use of the system is discussed further below.

\section{Scientific Progress: Effects of Aqueous Chemical Speciation and Activity on Olivine Carbonation Reactivity.}

We report here the first year results of the effect of aqueous solution species/activity on extent of carbonation using our $100 \mathrm{ml}$ batch carbonation reaction system at the standard conditions of 1 hour, $185^{\circ} \mathrm{C}, 2200 \mathrm{psi}$ of $\mathrm{CO}_{2}$ and stirring at $\sim 1500 \mathrm{rpm}$. In all these experiments, $15 \mathrm{wt} \%<38 \mu$ San Carlos olivine (essentially single crystal fragments) was used. The objective of these investigations is to further evaluate (i) the effect of aqueous chemical speciation and concentration on olivine passivating layer formation and carbonation reactivity and (ii) the potential controlling them offers to enhance carbonation. The primary focus is on the effect of alkali cation species and size (e.g., $\mathrm{Li}^{+}, \mathrm{Na}^{+}, \mathrm{K}^{+}$) and cation and anion activities. The results are 
compared to the extent of carbonation observed using the standard $0.64 \mathrm{M} \mathrm{NaHCO} 3+1.0 \mathrm{M}$ $\mathrm{NaCl}$ aqueous solution developed at the Albany Research Center (ARC). ${ }^{7}$ Initial investigations explored the effect of alkali cation species and concentrations by varying the alkali cations present with the standard aqueous bicarbonate and chloride concentrations in the sodium bicarbonate/sodium chloride solution developed by the $\mathrm{ARC}\left(0.64 \mathrm{M} \mathrm{AHCO}_{3}+1.0 \mathrm{M} \mathrm{ACl}\right.$, where $\mathrm{A}=\mathrm{Li}, \mathrm{Na}, \mathrm{K})$. Otherwise, the optimum conditions developed by the ARC were used.

Subsequent investigations discovered strong carbonation enhancement with increasing $\mathrm{NaHCO}_{3}$ and $\mathrm{KHCO}_{3}$ concentrations in the absence of the chloride solution, nearly doubling the extent of carbonation observed for the standard ARC solution. Cation speciation and concentration are also found to substantially impact carbonation, with mixed $\mathrm{Na}^{+} / \mathrm{K}^{+}$aqueous solutions showing promise for further enhancing carbonation. The carbonation extents reported are calculated based on elemental carbon analysis of the product materials and semi-quantitatively verified with Xray powder diffraction analysis. All of the product carbonate formed is identified as magnesite.

\section{Effect of Varying the Alkali Cation Species in the Standard ARC Aqueous Solution}

The effect of the alkali cation species and their activities on the extent of carbonation observed using the standard aqueous bicarbonate and chloride concentrations for the optimum solution developed by the ARC are shown in Table 1. The average extent of carbonation using the standard ARC solution (34\%) is shown in red. As both the bicarbonates and chlorides are completely soluble at the indicated concentrations, the reactions primarily differ in the alkali cation species present and their concentrations (i.e., $0.64 \mathrm{M}$ vs. $1.00 \mathrm{M}$, vs. $1.64 \mathrm{M}$ ). Clearly, the extent of carbonation is a strong function of both the alkali cation species and their activities. Perhaps the most intriguing observation is the strong effect of the $\mathrm{Na}^{+} / \mathrm{K}^{+}$ratio on extent of carbonation, with a 0.64 ratio resulting in $3 \%$ carbonation, while a 1.56 ratio $(1.00 / 0.64)$ yields $41 \%$ carbonation. The strong impact of the $\mathrm{Na}^{+} / \mathrm{K}^{+}$ratio on carbonation reactivity is further explored below, as it suggests significant potential to further enhance carbonation reactivity.

Table 1: Effect of Exchanging Alkali Cation Species in the Optimum ARC Aqueous Solution $(0.64 \mathrm{M} \mathrm{NaHCO}+1.00 \mathrm{M} \mathrm{NaCl})$ on the Extent of Carbonation

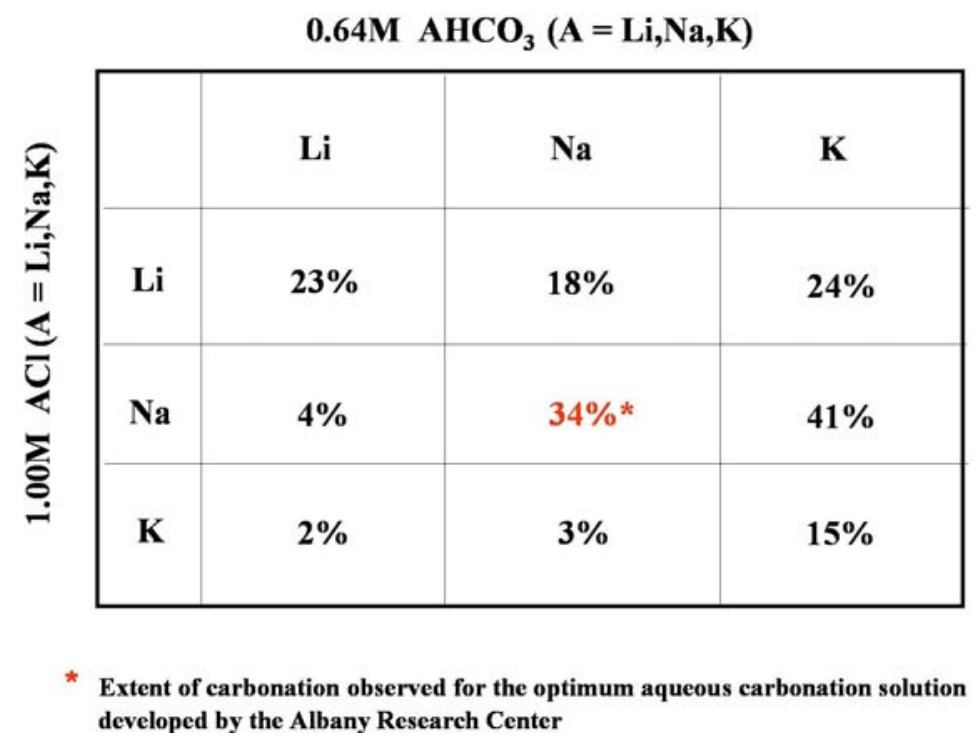




\section{Effect of the $\mathrm{Na}^{+} / \mathrm{K}^{+}$molar ratio, at constant $\left[\mathrm{HCO}_{3}{ }^{-}\right]$and $\left[\mathrm{Cl}^{-}\right]$}

Figure 1 shows that at $0.64 \mathrm{M} \mathrm{HCO}_{3}{ }^{-}$and $1.0 \mathrm{M} \mathrm{Cl}^{-}$, the carbonation reactivity of San Carlos olivine is a strong function of the $\mathrm{Na}^{+} / \mathrm{K}^{+}$molar ratio. This further underscores the impact that alkali cation speciation and activity can have on passivating layer effectiveness and carbonation reactivity. The extent of carbonation substantially increases with increasing $\left[\mathrm{Na}^{+}\right] /\left[\mathrm{K}^{+}\right]$ratio up to 1.56 and then falls off slightly to within experimental error of the average extent of carbonation observed for the standard $0.64 \mathrm{M} \mathrm{NaHCO}_{3}+1.0 \mathrm{M} \mathrm{NaCl}$ aqueous solution (33.6\%). At $\left[\mathrm{Na}^{+}\right] /\left[\mathrm{K}^{+}\right]=1.56$, the improvement in extent of carbonation appears to be significant, suggesting the associated alkali cation combination may better mitigate passivating layer formation and enhance carbonation. Combined with the above results, it is apparent that both the type and relative concentration of alkali cation species present in the aqueous solution can dramatically impact carbonation. The results also underscore the potential that combinations of alkali cation species can act synergistically to enhance carbonation. Based on the above results, we plan to further explore the potential that different combinations and concentrations of cation species offer to enhance carbonation during Year 2.

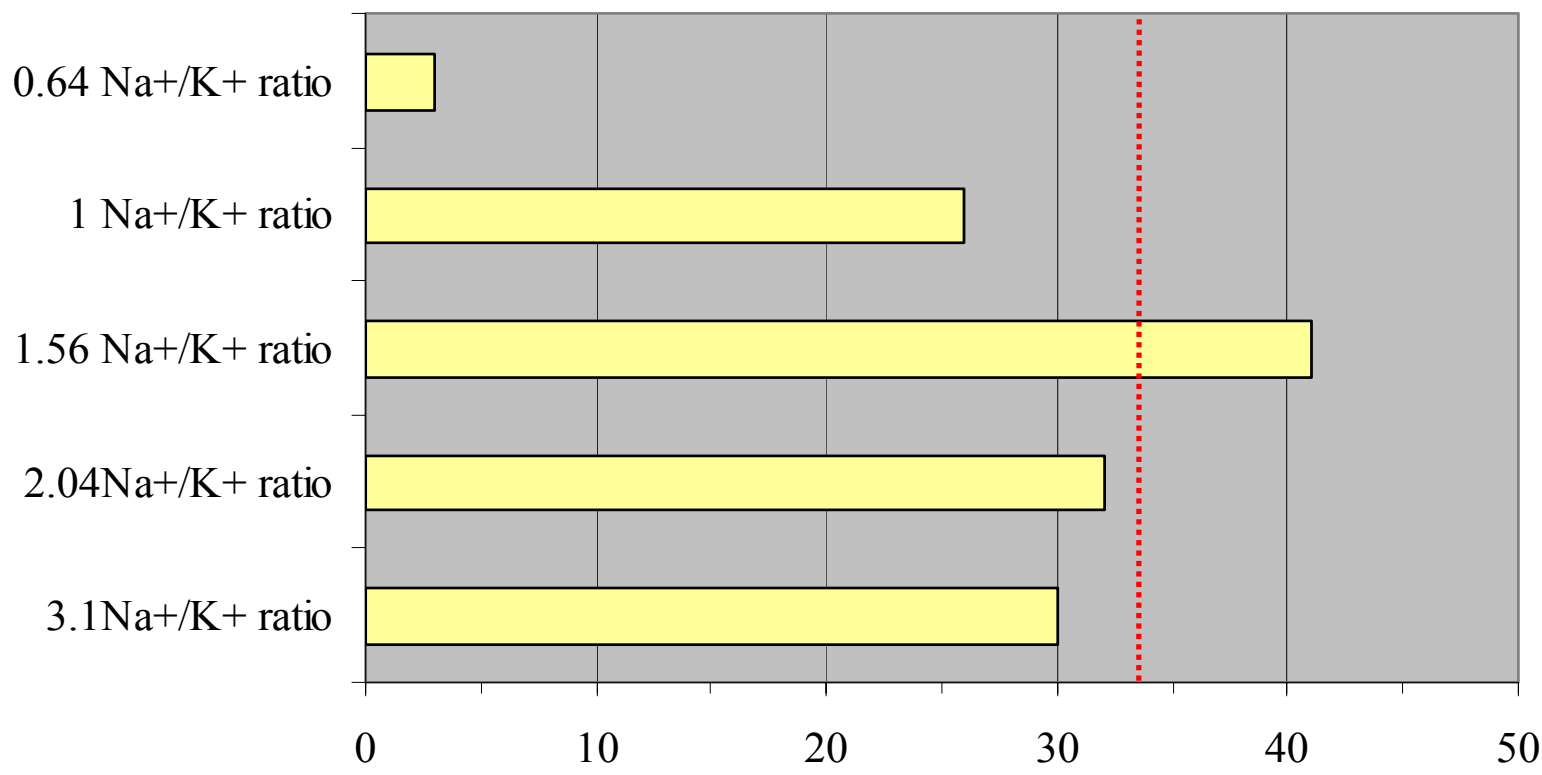

\section{Extent carbonation (\%)}

Figure 1: Extent of carbonation of San Carlos olivine as a function of $\mathrm{Na}^{+} / \mathrm{K}^{+}$molar ratio, at $0.64 \mathrm{M} \mathrm{HCO}_{3}{ }^{-}, 1.0 \mathrm{M}$ $\mathrm{Cl}^{-}$, and 1.64M $\mathrm{M}^{+}(\mathrm{M}=\mathrm{Na}+\mathrm{K})$. The dotted red line indicates the average extent of carbonation observed using the standard 0.64M $\mathrm{NaHCO}_{3}+1.0 \mathrm{M} \mathrm{NaCl}$ aqueous solution.

\section{Effect of varying alkali bicarbonate concentration $\left(\mathrm{NaHCO}_{3}\right.$ and $\left.\mathrm{KHCO}_{3}\right)$}

Two series of experiments were conducted for increasing sodium and potassium bicarbonate concentrations, due to their higher solubility limits relative to lithium bicarbonate under mineral carbonation reaction conditions. Figures $2 \& 3$ show the extent of carbonation observed as a 
function of $\left[\mathrm{MHCO}_{3}\right] \mathrm{M}=\mathrm{Na}$ or $\mathrm{K}$. In both cases, increasing the $\left[\mathrm{MHCO}_{3}\right]$ substantially increases the extent of carbonation, with $5.5 \mathrm{M} \mathrm{KHCO}_{3}$ nearly doubling the extent of carbonation in comparison with the standard $0.64 \mathrm{M} \mathrm{NaHCO}_{3}+1.0 \mathrm{M} \mathrm{NaCl}$ aqueous solution $(63 \%$ vs. $34 \%)$.

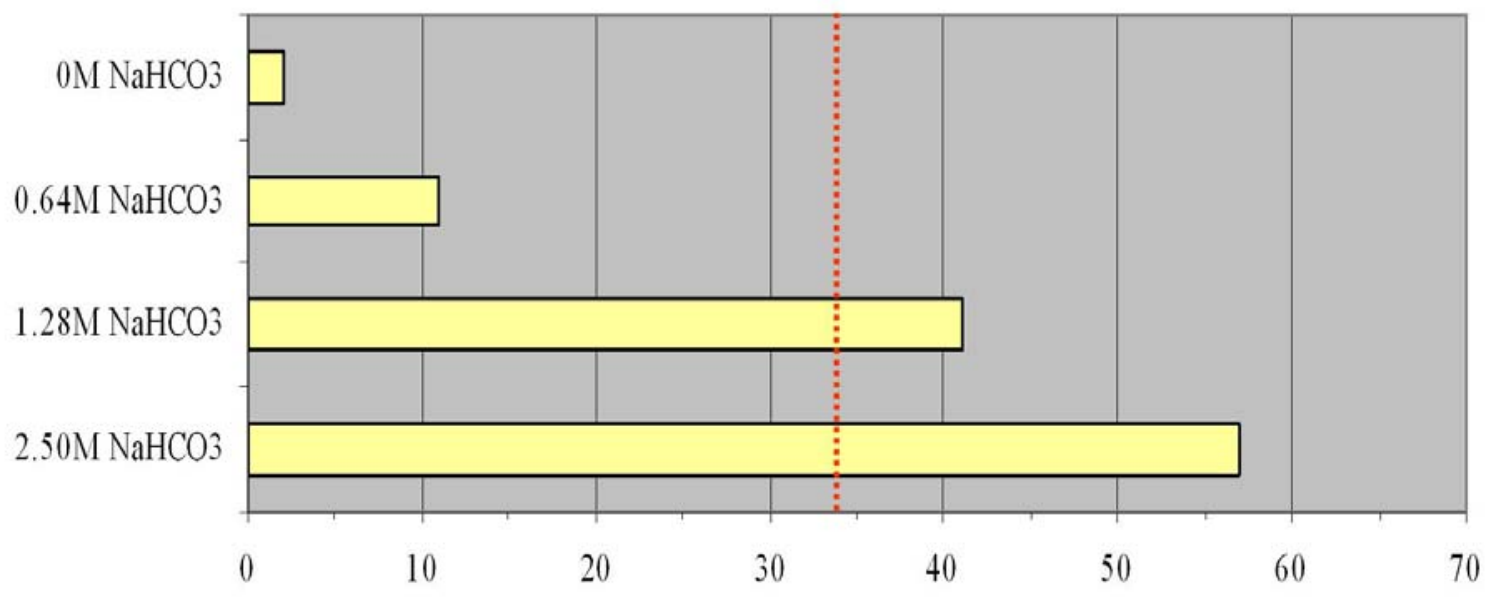

\section{$\square$ Extent carbonation (\%)}

Figure 2: Extent of carbonation as a function of $\mathrm{NaHCO}_{3}$ concentration, with no $\mathrm{Cl}^{-}$present. The dotted red line indicates the average extent of carbonation observed using the standard $0.64 \mathrm{M} \mathrm{NaHCO}+1.0 \mathrm{M} \mathrm{NaCl}$ aqueous solution.

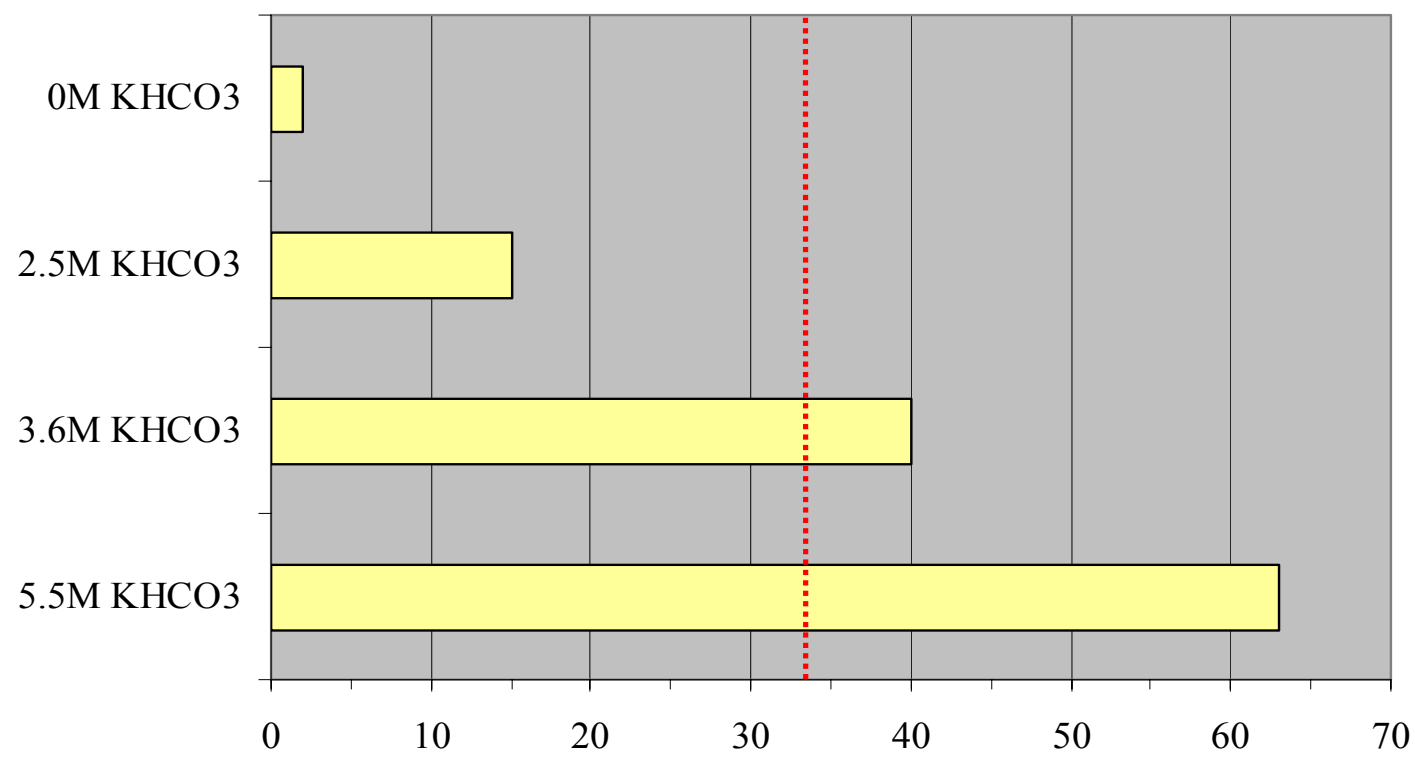

\section{Extent carbonation (\%)}

Figure 3: Extent of carbonation as a function of $\mathrm{KHCO}_{3}$ concentration, with no $\mathrm{Cl}^{-}$present. The dotted red line indicates the average extent of carbonation observed using the standard $0.64 \mathrm{M} \mathrm{NaHCO}+1.0 \mathrm{M} \mathrm{NaCl}$ aqueous solution. 
Both the $\left[\mathrm{HCO}_{3}^{-}\right]$and alkali cation species present substantially impact the extent of carbonation. This follows, for example, from the extent of carbonation observed for $2.5 \mathrm{M} \mathrm{NaHCO} 3(57 \%)$ being much higher than that observed for $2.5 \mathrm{M} \mathrm{KHCO}_{3}(15 \%)$, indicating $\mathrm{Na}^{+}$is substantially more effective than $\mathrm{K}^{+}$in mitigating passivating layer effectiveness and enhancing carbonation. It also follows from observations described below that alkali chloride solutions exhibit very poor carbonation reactivity, underscoring the importance of $\mathrm{HCO}_{3}{ }^{-}$. The importance of the alkali cation species is further underscored in Figure 4, where $7.5 \mathrm{M} \mathrm{RbHCO}_{3}$ was found to be substantially less effective in enhancing carbonation $(40 \%)$ than $5.5 \mathrm{M} \mathrm{KHCO}_{3}(63 \%)$ or $2.5 \mathrm{M}$ $\mathrm{NaHCO}_{3}(57 \%)$.

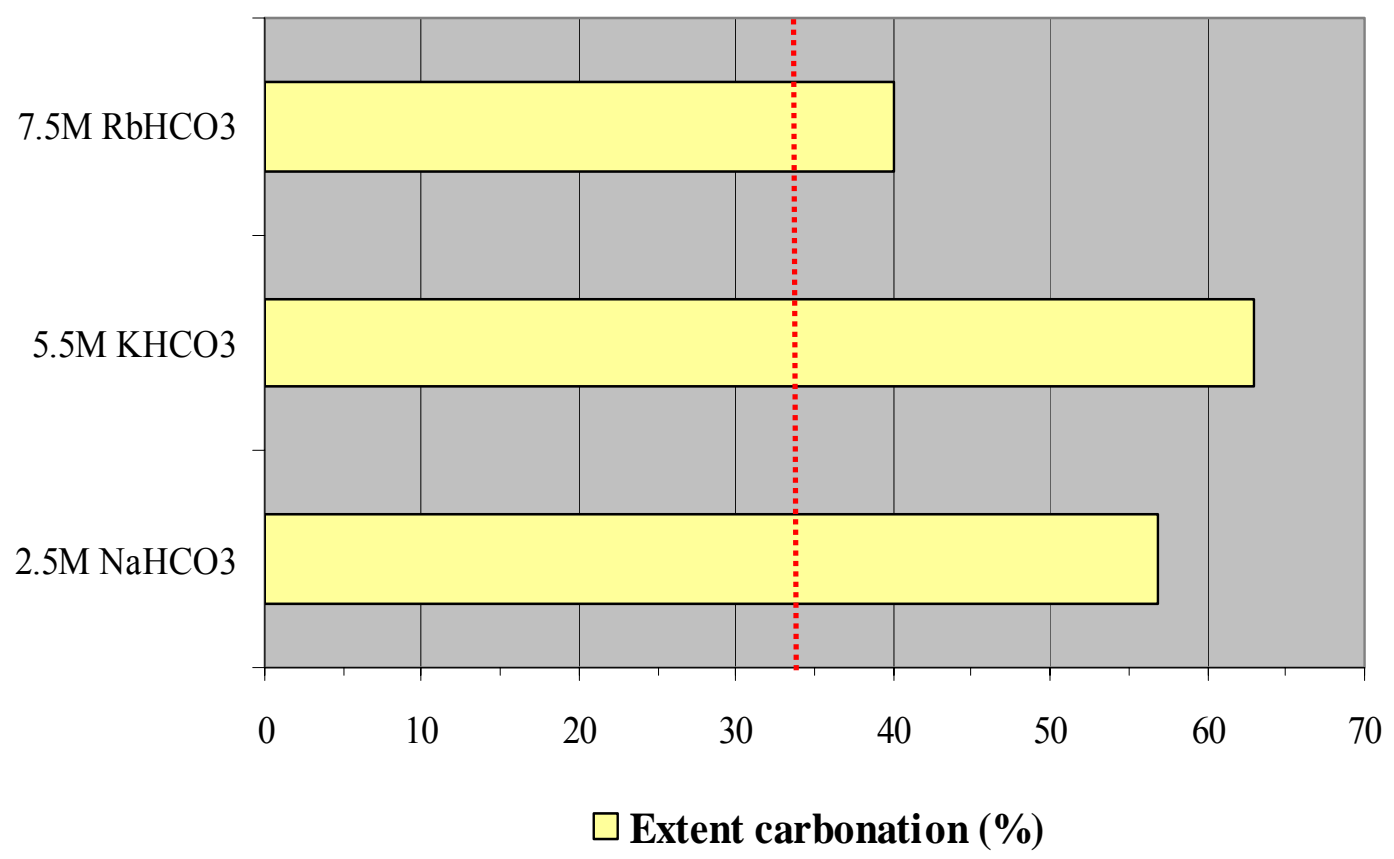

Figure 4: Effect of the different type/concentration of alkali bicarbonate on the extent of carbonation, with no $\mathrm{Cl}^{-}$ present. The dotted red line indicates the average extent of carbonation observed using the standard 0.64M $\mathrm{NaHCO}_{3}+1.0 \mathrm{M} \mathrm{NaCl}$ aqueous solution.

It is important to note that the above $\mathrm{NaHCO}_{3}$ and $\mathrm{KHCO}_{3}$ concentrations substantially exceed the aqueous solubility of $\mathrm{NaHCO}_{3}$ and $\mathrm{KHCO}_{3}$ under ambient temperature and pressure, $\sim 1.3 \mathrm{M}$ and $\sim 3.6 \mathrm{M}$, respectively, whereas the concentration of $\mathrm{RbHCO}_{3}$ is slightly lower than its ambient solubility of 7.9M. However, these solubilities may be expected to increase substantially with increasing temperature, with possibly small contributions from increasing pressure as well, allowing higher aqueous concentrations of $\mathrm{NaHCO}_{3}$ and $\mathrm{KHCO}_{3}$ to be utilized under mineral carbonation reaction conditions, as seen in Figures 2 and 3. However, the solubility under mineral carbonation reaction conditions will also be impacted by the activity of $\mathrm{CO}_{2}$ present, which may serve to inhibit alkali bicarbonate solubility. The potential for increased alkali bicarbonate solubility under reaction conditions motivated the above studies, even though the bicarbonate concentrations used exceed the solubility limits for aqueous sodium and potassium bicarbonate solutions under ambient conditions. We have not yet established whether we have reached the solubility limit for these solutions under reaction conditions. This will be 
explored in Project Year 2, as will be tests at lower temperatures and pressures (which can lower process cost, but can also impact $\mathrm{Na} / \mathrm{K}$ bicarbonate solubility). Year 2 studies will also include exploring the potential that the combined alkali cation effect offers to further enhance carbonation (e.g., will combined $\mathrm{NaHCO}_{3}+\mathrm{KHCO}_{3}$ aqueous solutions further enhance the carbonation reactivity observed for the individual $\mathrm{NaHCO}_{3}+\mathrm{KHCO}_{3}$ solutions).

\section{Comparison of the Extent of Carbonation Observed for 2,200 PSI $\mathrm{CO}_{2}$ and 5.5M $\mathrm{KHCO}_{3}$ Separately and Combined.}

Figure 5 shows the extent of carbonation observed for (i) distilled water under 2,200 psi $\mathrm{CO}_{2}$, (ii) $5.5 \mathrm{M} \mathrm{KHCO}_{3}$ under 2,200 psi $\mathrm{CO}_{2}$, and (iii) $5.5 \mathrm{M} \mathrm{KHCO}_{3}$ under 2,200 psi He. Clearly, the aqueous $\mathrm{KHCO}_{3}$ solution has a dramatic effect on carbonation reactivity, with very little carbonation observed using distilled water alone. In the absence of $\mathrm{CO}_{2}$, i.e., under $\mathrm{He}$, the carbonation reactivity drops substantially compared with that observed for $5.5 \mathrm{M} \mathrm{KHCO}_{3}$ under 2,200 psi $\mathrm{CO}_{2}$. Analysis of the $\mathrm{K}^{+}$concentration in the aqueous solution after the reaction is complete (diluted so that all the $\mathrm{KHCO}_{3}$ dissolves under ambient conditions) appears to provide interesting insight into the carbonation mechanism. Initial results indicate that no decrease is observed in the aqueous $\mathrm{K}^{+}$concentration after carbonation under 2,200 psi $\mathrm{CO}_{2}$, whereas a significant decrease is observed for $5.5 \mathrm{M} \mathrm{KHCO}_{3}$ under 2,200 psi He. This suggests that $\mathrm{KHCO}_{3}$ may not be consumed during carbonation under $\mathrm{CO}_{2}$. These results are preliminary at this point and need to be verified. Further solution analyses are also planned to determine the product aqueous solution bicarbonate concentrations.

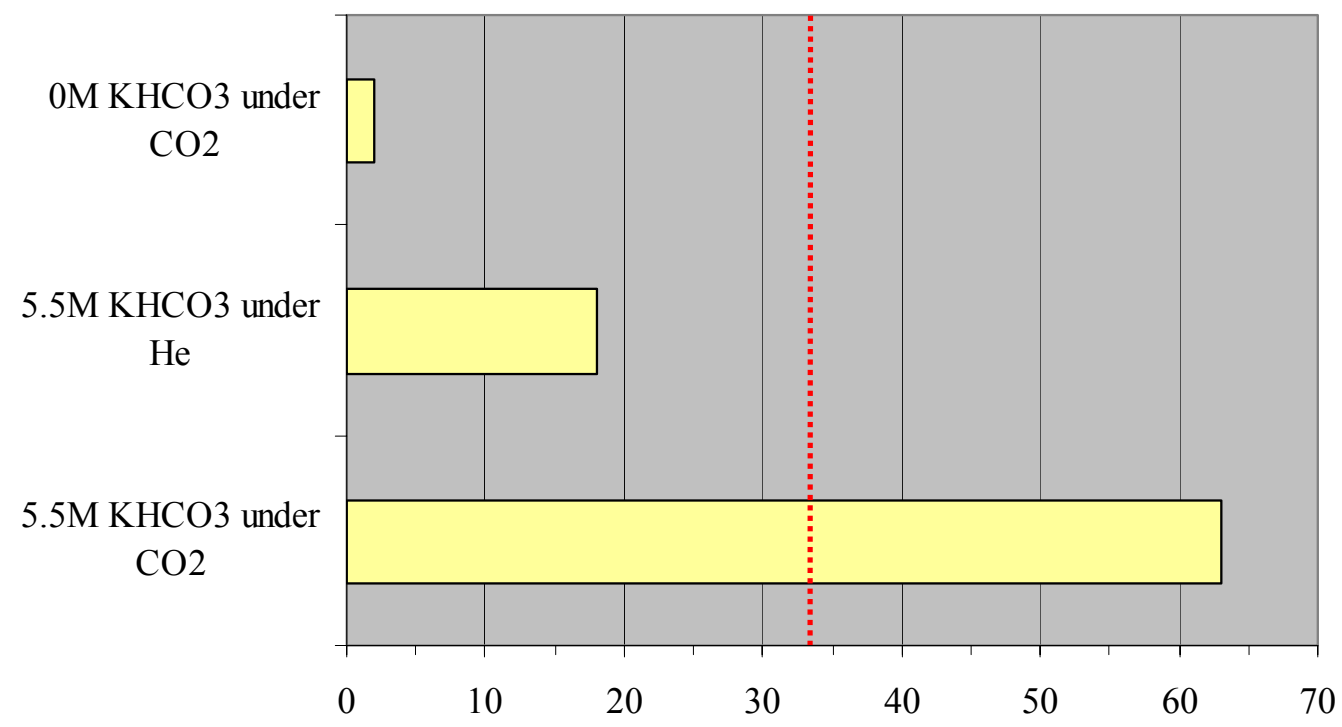

Extent carbonation (\%)

Figure 5: Extent of carbonation of San Carlos olivine reacted under 2,200 psi $\mathrm{CO}_{2}$ or He in the indicated aqueous solution. Distilled water is represented as $\mathrm{OM} \mathrm{KHCO}_{3}$ solution. The dotted red line indicates the average extent of carbonation observed using the standard 0.64M $\mathrm{NaHCO}_{3}+1.0 \mathrm{M} \mathrm{NaCl}$ solution. 
In the second project year, work exploring the impact that aqueous solution chemistry can have on enhancing carbonation reactivity will emphasize further exploration of the potential that combined alkali cation species offer to enhance carbonation using both pure bicarbonate solutions and solutions that incorporate alkali chloride and bicarbonate.

Scientific Progress: Multi-phase Fluid Modeling and Experimental Investigations to Elucidate Key Slurry-Flow Parameters that Enhance Exfoliation and Carbonation

Work in this area of the project has focused on two hierarchies of fluid-flow modeling in addition to experiments focusing on particle-size effects. The over-arching aim of the investigations in this portion of the project is to attempt to isolate and to understand effects that may be crucial to optimizing the fluid dynamics of sequestration processes to enhance passivating layer exfoliation and carbonation. One of the two hierarchies of fluid flow modeling focused on "microscopic" modeling of particle-laden flows in which the aim was to investigate stochastic approaches to representing wall roughness. "Macroscopic" modeling approaches were applied to predict the behavior in reactor sections in which the aim is to assess/incorporate current engineering models to predict the average properties of liquid-solid turbulent flows. As described in greater detail below, these calculations were performed using Fluent and applied to conditions representative of those in the flow-loop reactor at the Albany Research Center. The third phase of the effort that was initiated during Year 1 was analysis and design of experiments performed at ARC and ASU in which the main goal is to quantify and understand particle size effects on carbonation levels. The primary aim of efforts in this area of the project during Year 2 will be further analysis and publication of the experimental measurements focusing on particle size effects and macroscopic fluid flow modeling that will be used for parametric studies of the effect of flow rate, solids loading, and particle size on the average properties of liquid-solid mixtures representative of those encountered in mineral sequestration applications.

\section{1. "Microscopic" Fluid Flow Modeling}

Fluid flow dynamics in industrial flow loop reactors (such as simulated by the lab scale reactor at the Albany Research Center) result in complex interactions between the suspended solids phase, fluid carrier flow, and reactor surfaces. Particle-particle interactions (e.g., surface abrasion by particle friction from rubbing and/or collisions) and particle-wall interactions contribute to passivating layer exfoliation and carbonation. Wall roughness, flow rates (i.e., Reynolds numbers), solids loading, and particle size distributions provide examples of those parameters whose influence on transport and exfoliation are not well understood. Computational models are essential to advancing the understanding of their effects and eventually for use in carbonation process design and optimization.

The specific aim of the work on "microscopic" modeling focused on wall roughness and representing the effects of rough surfaces on particle transport. The modeling in this phase of the work is referred to as "microscopic" since it considered the motion of individual particles, in contrast to the "macroscopic" modeling described in the section that represents the averaged properties of the particulate phase by solving field equations rather than using Lagrangian tracking of individual particles. 
Particle tracking approaches were employed in simulations of a geometrically simple flow but still possessing the complicating effects of mean shear in each phase and the presence of solid surfaces. The primary contribution of this part of the work was development of a stochastic model of wall roughness that accounts for the transfer of mean-to-fluctuating particle momentum arising from the impact of a particle with a roughened surface. In particular, in the model that was developed a particle collides with a "virtual wall" which has a randomly distributed inclination with respect to the plane, smooth wall (c.f., Figure 6). The "wall roughness angle" is denoted $\gamma$ in Figure 6 and is sampled from a Gaussian distribution. The stochastic treatment is similar to that employed in Sommerfeld and other related references. ${ }^{11}$ Simulations were performed to test the model using three values of the standard deviation, $\gamma^{6}$, of the distribution of wall roughness angles: $0^{\circ}$ (smooth wall), $2.5^{\circ}$, and $5^{\circ}$. These values are within the range of the measurements from Sommerfeld and Huber used to develop and validate roughness models for Lagrangian particle tracking approaches. ${ }^{12}$

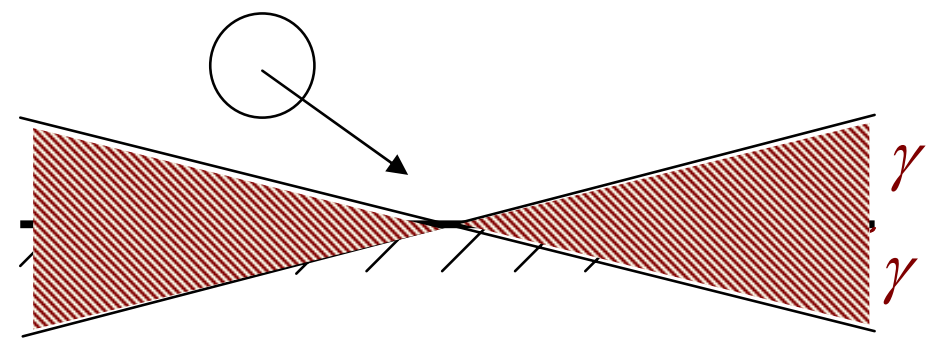

Figure 6. "Virtual wall” with random orientation, $\gamma$

The flow used to test the roughness model was a vertical, fully-developed turbulent channel flow. The numerical approach is based on Large Eddy Simulation (LES) of the carrier-phase flow and Discrete Particle Simulation (DPS) for prediction of dispersed phase transport. Particle motion is controlled by interactions with the surrounding fluid flow, interactions with other particles (collisions), and interactions with the (roughened) channel walls. The particle diameters are small (specified as one viscous unit), corresponding to diameters of approximately $90 \mu \mathrm{m}$ in applications. The numerical model was idealized and represents a limit case which highlights the effect of surface roughness on particle transport and is well suited for the purpose of assessing the model. Effects such as lubrication forces between particles and the wall were not accounted for in the simulations.

A representative sample of results highlighting the effect of wall roughness is shown in Figure 7. Shown in the figure is the wall-normal profile of the mean particle number density for a heavy particle, i.e., a particle that does not respond to the majority of the turbulent fluctuations of the carrier-phase flow. For the results shown in the figure the influence of particle-particle collisions was not included and therefore the difference in the profiles is due solely to the effect of wall roughness. The curves in the figure are for a smooth-wall case $\left(\gamma=0^{\circ}\right)$ and rough-wall case with $\gamma=2.5^{\circ}$. The figure shows that for particle-wall collisions with a smooth wall, the number density distribution peaks at the wall as typically observed in channel flow in which particle-particle collisions are not considered and for which there is a specular reflection of the particle on the wall. Under the influence of wall roughness the number density distribution 
becomes more uniform across the channel, indicative of a greater mixing of the particles across the channel, again arising solely due to the effect of wall roughness. Though not shown here, for lighter particles (e.g., lower particle material density) the influence of wall roughness on the concentration profile (number density) is less significant than shown in Figure 7 . Lighter particles follow more closely the velocity fluctuations of the carrier-phase flow and impact the wall at shallower angles (grazing-type wall collisions) and also possess, on average, lower streamwise velocities compared to the heavy particles. These factors in turn lessen the effect of wall roughness on their transport since there are fewer wall collisions and a less significant transfer of streamwise particle momentum to the wall-normal fluctuations of the particle velocity that facilitate particle-particle collisions. The difference in response to wall interactions as a function of particle size suggests that relatively broad reactant particle size distributions should favor particle-particle interactions, exfoliation and carbonation by promoting momentum vectors with a greater probability of intersection. As a result, we have begun to explore the effects of particle size distribution, with our initial experimental investigations indicating that broader size distributions can favor carbonation, as described below.

The effect of wall roughness on the streamwise component of the mean particle velocity is shown in Figure 8, again for the heaviest particles used in the tests of the roughness model. Shown in the figure is the profile of the mean fluid velocity on the Eulerian grid used to resolve the fluid flow, the mean fluid velocity around the particles, and the mean particle velocity for the smooth and rough-wall cases. For the smooth-wall case the mean slip between the particles and fluid is small and, consequently, the mean velocity of the particles is close to that of the fluid. Analogous to the more uniform profiles achieved in the number density in Figure 7, for cases in which particles collide with rough walls, Figure 8 shows that the particle mean velocity profile develops a sharper gradient in the near-wall region. The figure also shows that the particle velocity slips relative to the surface (i.e., is not zero), which is compatible with the elastic bouncing of the particles on the wall as considered in the current simulations. Also, not shown, the radial fluctuating particle velocity is increased by wall roughness. Consequently, wall roughness induces a greater cross-stream transport that will promote particle-particle and particle-wall collisions, in addition to greater mixing with the aqueous phase. In particular, the resulting increase in the number of and momentum transfer associated with particle collisions is expected to lead to enhanced exfoliation and carbonation.

In summary, the simulations used to assess "microscopic" fluid flow modeling illustrate that particle transport and mixing can be enhanced by interactions with roughened surfaces. While the current simulations used to assess the roughness model are idealized, in order to enable the application of simulation techniques that resolve turbulent fluctuations, the computations illustrate the importance of the basic effect of roughness, which is to transfer the mean streamwise momentum of the particles to the fluctuating velocities that are normal to the surface. This is an important mechanism for enhancing transport across the entire channel and facilitating particle-particle and particle-wall collisions, exfoliation and carbonation.

\section{Macroscopic Fluid Flow Modeling}

Advances in computational fluid mechanics have provided the basis for advanced prediction of the dynamics of multiphase flows. Various approaches exist to solving multiphase flows, some of which focus on tracking individual particles, as highlighted in the previous section on 


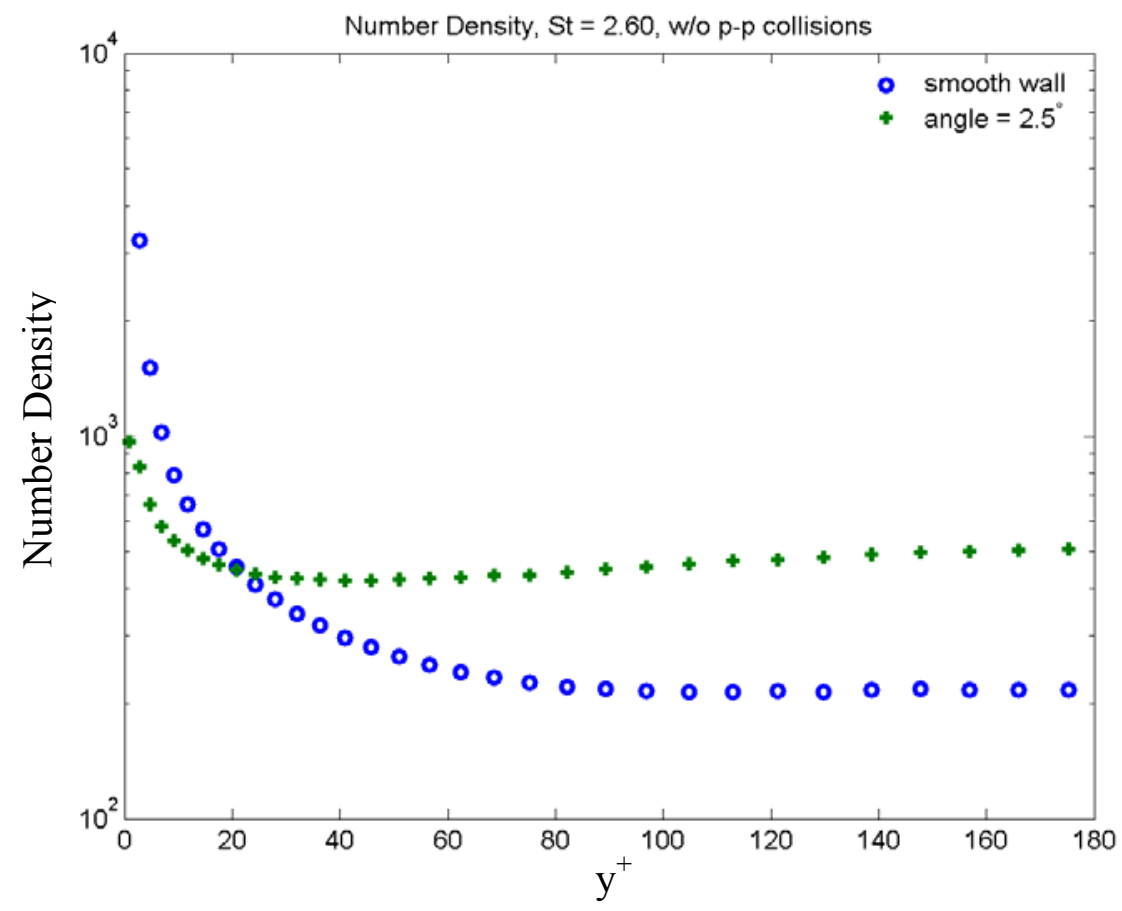

Figure 7. Roughness influence on mean number density. $y^{+}$represents the distance from the wall during cylindrical pipe flow. 180 represents the pipe center.

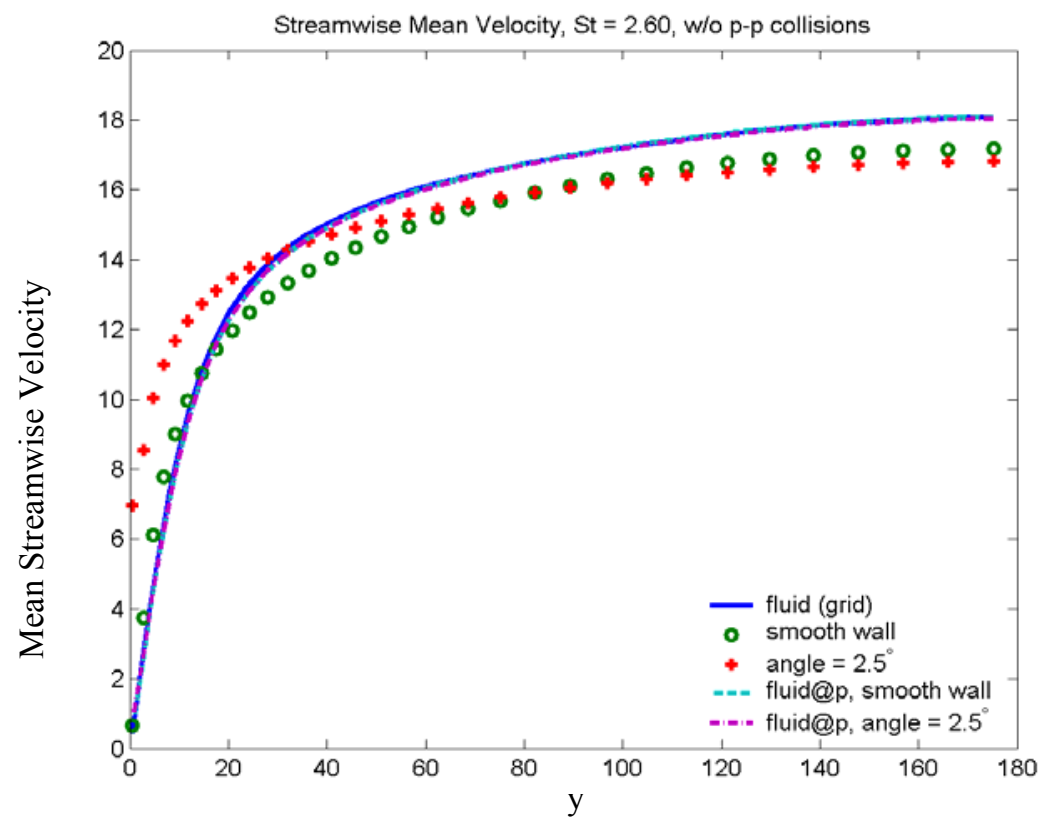

Figure 8. Roughness influence on streamwise velocity. Fluid (grid) represents the fluid flow mean velocity on the grid. Fluid@p denotes the mean fluid velocity in the vicinity of the particle. Smooth wall represents the particle velocity in the smooth wall model. Angle $=2.5^{\circ}$ similarly represents the particle velocity in the $2.5^{\circ}$ model. 
"microscopic" modeling. Other approaches treat each phase (aqueous carrier flow and dispersed particulates) as continua, referred to as an "Eulerian approach" or "two-fluid" method. The Eulerian approach is adopted in this portion of the work focusing on "macroscopic" modeling in which the aim is to predict the bulk properties of the flow such as the mean velocity, mean pressure drop, and averaged volume fractions.

The simulations performed in this phase of the work are primarily guided by the experiments conducted in the ARC flow loop reactor in collaboration with Larry Penner at the Albany Research Center. In these experiments, approximately 420 grams of finely ground olivine ore is used as a feedstock sample. As a rough estimate, if we consider a mean particle diameter of $30 \mu \mathrm{m}$, the number of particles in the feedstock sample is approximately $9 \mathrm{e}+9$. Attempting to solve the Navier-Stokes equations for the carrier fluid (the heterogeneous mixture of the aqueous solution and $\mathrm{CO}_{2}(\mathrm{sc})$ phases) and then using Lagrangian tracking of individual particles is unwieldy. The Eulerian approach, which does not attempt to track individual particles, provides a more computationally efficient method.

In the Eulerian approach, the different phases are treated mathematically as interpenetrating continua. The volume fraction of each phase is assumed to be continuous functions of space and time and their sum is equal to one. Fluid and energy conservation equations for each phase are derived to obtain a set of equations, which have similar structure for all phases. A set of momentum and continuity equations are solved for each phase. These equations are closed by providing constitutive relations that are obtained from empirical information. Coupling between the phases is achieved through pressure and interphase exchange coefficients.

Accurate prediction of flow properties such as the mean velocity, pressure drop, and volume fraction distributions at different zones in the flow loop reactor can provide insight into the behavior of the system and hence might prove useful to understanding the dynamics influencing the extent of carbonation observed in the sequestration process.

The flow solution is obtained using a Phase Coupled Semi-Implicit Method for Pressure Linked Equations (PC-SIMPLE) algorithm. ${ }^{13}$ As an example, the computation requires approximately 20000 iterations to arrive at a steady state solution for a particle laden multiphase flow in a 32" long, Schedule 80 pipe with an inner diameter of 0.546 ". This calculation corresponds to a grid generated with 400 points along the streamwise direction (parallel to the flow) and 30 points in the radial direction (perpendicular to the flow). This, when converted to time, translates to approximately 8 hours on a Pentium 4 processor running at $2.8 \mathrm{GHz}$ and with $1 \mathrm{~GB}$ RAM.

The flow loop reactor at Albany is equipped with four gauges to measure the pressure drop across various sections of the reactor. The most consistent set of measurements are acquired from gauges mounted across two points 32" apart. Hence, the multiphase flow simulations were carried out using pipe dimensions having the same specifications as this leg of the flow loop reactor at ARC.

Initial computations modeling the flow loop reactor were of the flow in a straight pipe, 32 " long and with an inner diameter of 0.546". The computations then progressed to a higher level of geometric complexity by adding a block in the flow, which mimics the presence of a flow mixer 
that is installed in the flow loop to enhance mixing of the fluid and dispersed phases and, consequently, enhance reaction. The next level of complexity of the numerical model incorporated a pipe section with two different diameters in the same length of pipe, in turn accounting for the change of the pipe diameter from Schedule $80(0.546$ " inner diameter $)$ to Schedule 40 (0.63" inner diameter) (Figure 9) as present in the actual flow loop reactor.

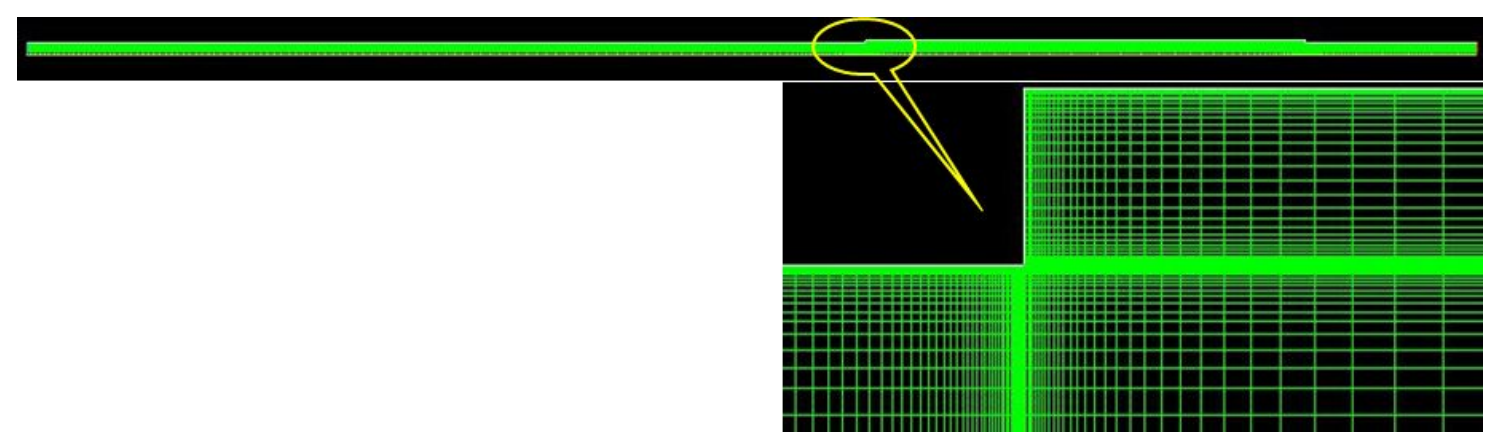

Figure 9. Cross-section of pipe with zoomed in view of changing diameter. The upper part of the figure shows a low resolution image of the pipe, with a close up of the transition from the schedule 80-40 transition shown below. Both images represent axial cross sections of the upper half of the pipe.

Given the intricate design of the mixer, which is formed by bolting together small interweaving twisted plates, it is not feasible to model the intricate features of the geometry directly. Instead, the effect of the mixer is modeled as a porous media. Mathematically, the momentum of the flow is reduced by adding a sink to the momentum equations in the porous region of the pipe.

As summarized below, computations were performed with and without the solids phase in order to assess the influence on quantities such as pressure drop. Recent efforts, also summarized below, have focused on changing the particle volume fraction distribution by modeling ribs along the inner wall of the pipe geometry. Flow simulations using ribs have revealed dramatic changes in the particle concentration distribution by the inclusion of ribs along the inner lining of the pipe wall. While preliminary, these results might highlight a possible re-design of the reactor which may enhance carbonation, while avoiding flow mixers, which require cleaning after each run. This may eliminate or reduce the cleaning cycles required using the current design, lowering the cost of system operation. All the computations consider fluid flow through a pipe and are used to assess the effect of physical parameters (e.g., the volume fraction) and numerical procedures used to assist the convergence of the system of equations.

Modeling Strategy: The two-phase (fluid-solid) modeling so far has consisted of analyzing the flow comprised of a mixture of a fluid having properties (density and viscosity) similar to those of a combined mixture of the aqueous solution and supercritical $\mathrm{CO}_{2}$ under reaction conditions and finely ground olivine ore. The density calculations for the fluid mixture assume a solution formed by the aqueous and supercritical $\mathrm{CO}_{2}$ components in the ratio of $90 \%-10 \%$ by volume. The solid phase was represented by particles of diameters $37 \mu \mathrm{m}, 75 \mu \mathrm{m}$ and $150 \mu \mathrm{m}$ and having a density of $3300 \mathrm{~kg} / \mathrm{m}^{3}$. Given the symmetry conditions, an axi-symmetric geometry was modeled, and a cross-section of a plane cut along a direction parallel to the flow was meshed. Figure 10 highlights the porous region in the pipe indicating the zone where the mixer is present. 


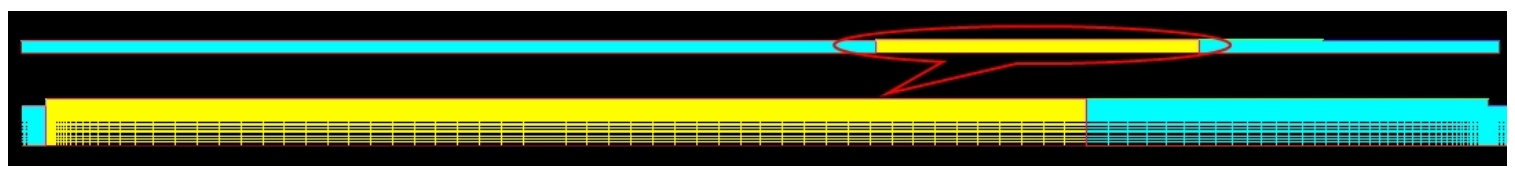

Figure 10. Reactor with a 7" long porous zone indicating the presence of mixer. The upper part of the figure shows a low resolution image of the pipe containing the yellow porous region, with a close up of the associated region shown below. Both images represent axial cross sections of the upper half of the pipe.

Turbulence modeling is accomplished using the standard two equation $k-\varepsilon$ model with standard values of model constants. Tests to assess the computational procedures (e.g., to calibrate numerical parameters used to ensure convergence of the equations to steady state) have been performed. Certain assumptions have been used for the modeling exercise, most important of which are absence of reactions (due to limitations imposed by the software to solve for reaction and fluid flow simultaneously), no mass transfer, uniform mass flow rate and no roughness along the inner surface of the pipe. The equations are initially converged using a first-order accurate numerical method, which is numerically efficient although not sufficiently accurate. At convergence, the numerical method is switched to an accurate second-order scheme and the simulation continued until convergence is achieved. Initial validation of the computations were based on comparison of predicted pressure drop against the standard Lockhart and Martinelli correlation for predicting pressure drop in mixtures that characterize flow loop reactors. ${ }^{14}$ The numerical simulations considered a single particle diameter.

Table 2 shows the pressure drop $(\delta \mathrm{P})$ results obtained using the porous model without particles in the flow. The comparison shown is made against a similar experimental run with the mixer in the pipe using pressure drop measurements from the flow loop reactor. The porous model employs constants that can be used to initially calibrate the simulation in order to account for effects such as porosity, with refinement done via comparison with empirical data. The CFD predictions in Table 2 were obtained by adjusting the initial constants in order to closely match the experimental measurements at $3.5 \mathrm{gpm}$. Once calibrated, the model was run for other flow rates; Table 2 shows that the variation of the pressure drop with flow rate is essentially linear.

Table 2. Pressure drop measurements for cases with mixer and without compared with average pressure drop measurements from reactor runs at $185^{\circ} \mathrm{C}$ and $2200 \mathrm{psi}$.

\begin{tabular}{|c|c|c|}
\hline \multicolumn{3}{|c|}{ Porous media model results (without particles) } \\
\hline $\begin{array}{l}\text { Mass flow } \\
(\mathrm{gpm})\end{array}$ & $\begin{array}{l}\text { SP (psi) 32" long pipe with porous zone } \\
\text { (parentheses values without mixer in pipe) } \\
\text { CFD predictions }\end{array}$ & $\begin{array}{l}\text { SP (psi) using reactor data run at } \\
185 \mathrm{C} \text { and } 2200 \mathrm{psi}\end{array}$ \\
\hline 2.0 & $0.79(0.08)$ & \\
\hline 3.0 & $1.40(0.15)$ & \\
\hline 3.5 & $1.72(0.21)$ & 1.69 \\
\hline 4.0 & $2.00(0.27)$ & \\
\hline
\end{tabular}


Flow rate measurement and pressure drop data that are planned to be obtained in the second year of this project will be used to further refine the model.

Figure 11(a) shows a plot of volume fraction distribution of the olivine particles as a function of their diameter and the radial distance from the pipe center. Shown in Figure 11a is the volume fraction distribution plot down stream from the porous mixer, which is still 18" removed from entering the next mixer (in the flow-loop reactor). The plots are generated for size fractions of $37 \mu \mathrm{m}, 75 \mu \mathrm{m}$, and $150 \mu \mathrm{m}$. Figure 11(a) indicates that the particle distribution has largely recovered from the effects of passing through the mixer well before encountering the next mixer. This in turn can dramatically reduce the probability of particle collisions and passivating layer exfoliation over more than half of the length of the reactive transport. This suggests an alternative approach of incorporating more, smaller mixers spaced at closer intervals to more effectively enhance particle collisions and exfoliation throughout the reaction transport region.

The near wall particle volume fraction concentration in Figure 11a is higher than the other regions of the pipe. This pattern was observed for each size fraction modeled. While this effect is displayed by all size fractions, the larger size fraction exhibits this behavior more prominently than the smaller size fractions, consistent with the slower recovery of the larger particles to the more uniform profile achieved by the smaller particles. This is further consistent with the ability of the larger particles to better retain their cross-stream velocity component, which can further enhance particle collisions and exfoliation.

A possible configuration to promote more uniform and sustained mixing, optimizing particle collisions and exfoliation in the process, could be based on the substitution of ribs (Figure 12) or studs at frequent equidistant intervals along the inner walls of the reactor pipes. This structural modification is currently being modeled to explore if it can induce higher inter-particle interaction, which can translate to higher carbonation rates. Including such ribbed pipes in the flow loop reactor may also reduce the need for periodic cleaning of the reactor further reducing process cost.

As a first step towards using the simulations for such studies, the domain was modeled with two ribs $0.15 "$ high and 0.5 " thick along the inner pipe wall. The particle volume fraction distribution at the exit with and without the ribs are shown in Figure 11(b) for different size fractions. Comparison of Figures 11(a) and 11(b) indicate that the presence of the ribs has drastically altered the solid volume fraction distribution, substantially enhancing particle concentrations downstream from mixing. It is also important to note the enhanced cross-stream velocity component suggested downstream from the ribs, which can lead to enhanced particle interactions and exfoliation. Since the flow solver does not hold the potential to solve for both the reactivity and the flow simultaneously, effect of ribs on the reactivity enhancement is subject to experimental verification. Increasing particle concentrations have been separately associated with enhanced carbonation reactivity using the flow loop reactor and the ASU batch reactor, as discussed below. This observation will be further explored during the second year of 


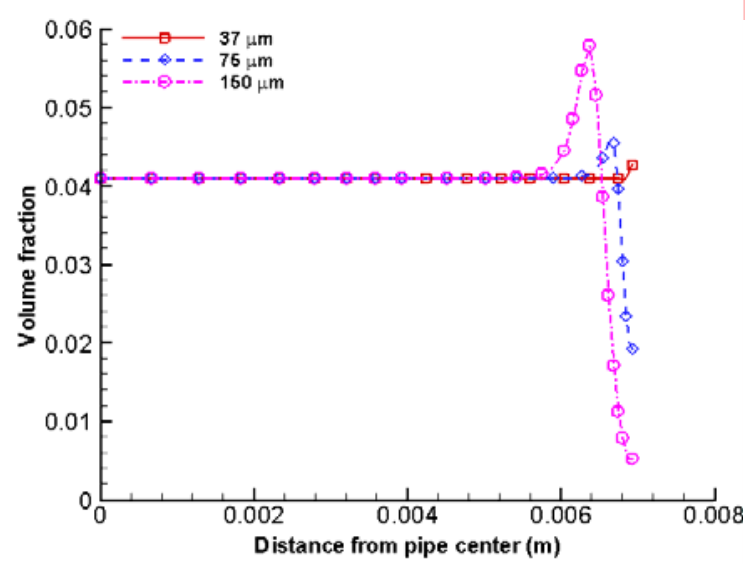

(a)

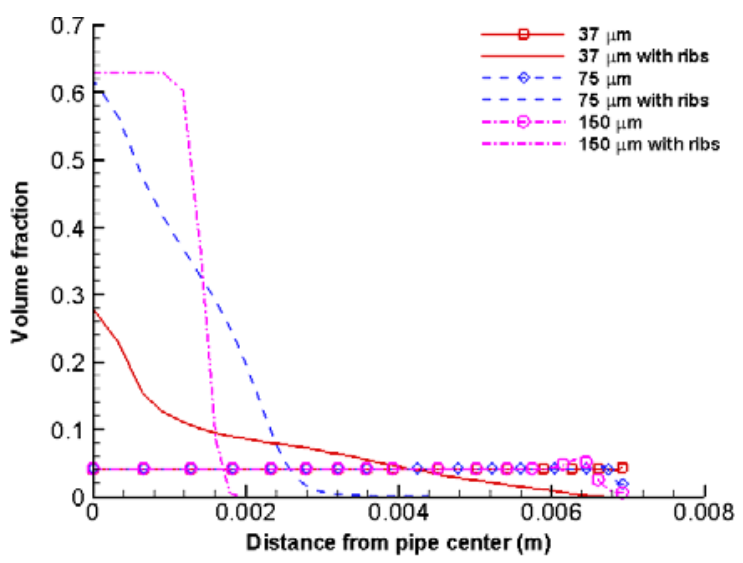

(b)

Figure 11. Volume fraction distribution of olivine at exit of pipe (a) Simulation without ribs for 3 size fractions (b) Comparison for simulation with ribs for the same size fractions.

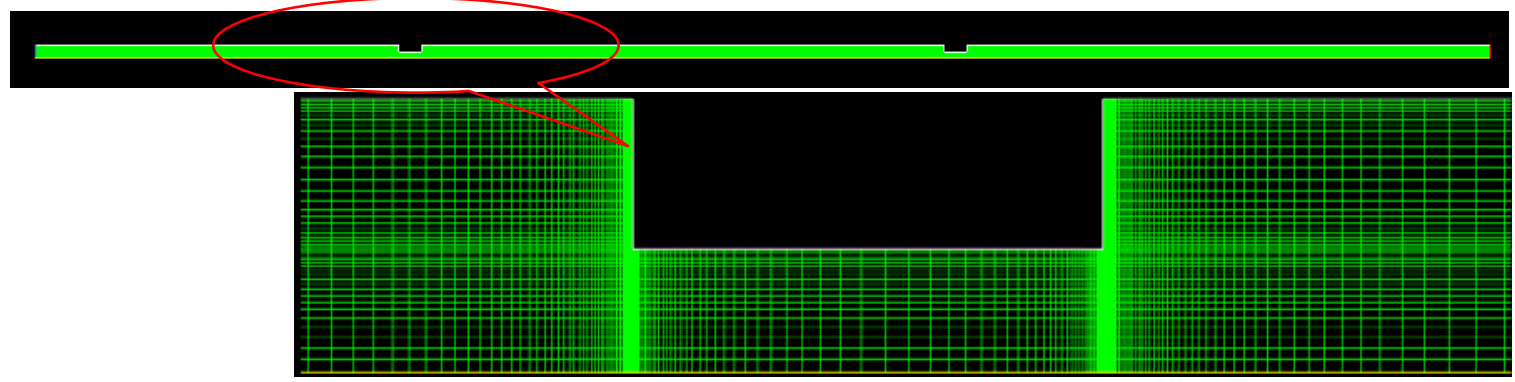

Figure 12. Cross-sectional profile of the axi-symmetric pipe with ribs included in the geometry. The upper part of the figure shows a low resolution image of the pipe, with a close up of the section highlighted shown below. Both images represent axial cross sections of the upper half of the pipe.

the project, to further evaluate the potential that ribs offer to enhance particle interactions, exfoliation and carbonation. Efforts are underway to simulate the flow in the $100 \mathrm{ml}$ ASU batch reactor with a primary objective to study the distribution of olivine particles. The distribution of the particles in the ASU reactor may shed some light on collision processes and in turn be useful for comparing the extent of carbonation observed using the Flow-Loop reactor at ARC and the batch reactor at ASU.

\section{The Effects of Particle Size and Particle Size Distribution}

The above modeling investigations indicate that the reactant particle size distribution may be a key factor impacting particle collision frequency, momentum transfer, exfoliation and carbonation. During the first year of this project we explored the effect of particle size distribution using the ASU batch reactor and began partner studies in collaboration with Larry Penner to explore the effect of size distribution using the ARC Flow-Loop reactor. Initial observations vs. particle size using the Flow-Loop reactor are given in Figure 13. 
Initial Studies of the Effect of Pump Speed and Particle Size On Olivine Carbonation in the ARC Flow Loop Reactor

\begin{tabular}{|c|c|c|}
\hline Pump Speed (rpm) & Particle Size Fraction & Extent of Carbonation \\
\hline 1198 & $<400$ mesh (baseline) & $72.0 \%$ \\
\hline 1002 & $<200$ mesh & $66.9 \%$ \\
\hline 1198 & $<200$ mesh & $63.2 \%$ \\
\hline 1450 & $<200$ mesh & $73.8 \%$ \\
\hline 1750 & $<200$ mesh & $77.9 \%$ \\
\hline
\end{tabular}

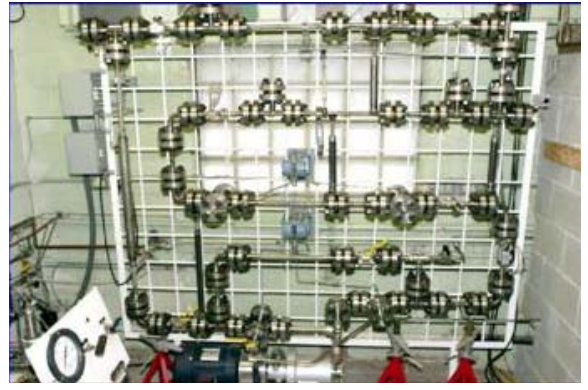

ARC Flow Loop Reactor

Figure 13. The ARC Flow-Loop reactor (right) together with the initial extent of carbonation observed for $<400$ mesh and $<200$ mesh Twin Sisters olivine feedstock.

Preliminary observations of carbonation vs. particle size fraction using the ARC flow-loop reactor (Figure 13) indicate that the extent of carbonation can remain quite high for larger feedstock particles. As the large majority of the grinding cost associated with preparing the $<400$ mesh feedstock comes in reducing the material from $<200$ mesh to $<400$ mesh, the ability to effectively carbonate larger $<200$ mesh olivine feedstock can substantially reduce process cost. Further collaborative studies as a function of particle size distribution using the ARC flowloop reactor have been initiated and will continue in Year 2, to further explore the potential controlling particle size distribution offers to reduce process cost.

We also initiated investigations as a function of particle size fraction using the ASU batch reactor as described below. Single crystal San Carlos olivine fragments are incorporated as the feedstock material. The associated carbonation runs were carried out using the standard ARC solution $\left(1 \mathrm{M} \mathrm{NaCl} \& 0.64 \mathrm{M} \mathrm{NaHCO}_{3}\right)$ and reaction conditions ( 1 hour at $185^{\circ} \mathrm{C}$ under $2200 \mathrm{psi}$ of $\mathrm{CO}_{2}$, with $1500 \mathrm{rpm}$ stirring). The list of these experiments, their conditions and the extent of carbonation in each are given in Table 3 . The average extent of carbonation for 4 runs with the standard feedstock material $(<38 \mu)$ and two runs each for each particle size fraction are shown, with $34 \%$ carbonation observed for the baseline $<38 \mu$ material. The relatively low overall extent of carbonation observed can be related to the single crystal nature of the feedstock particles used herein to facilitate mechanistic observations of passivating layer formation/exfoliation.

\section{Table 3. Extent of Carbonation Observed as a Function of Particle Size Distribution using San Carlos Olivine and the ASU Batch Reactor}

Seri
1
2
3
4
5

\section{Feedstock Particle Size Fraction}

$$
\begin{aligned}
& <38 \text { micron } \\
& 38-75 \text { micron } \\
& 75-150 \text { micron } \\
& <75 \text { micron } \\
& <150 \text { micron }
\end{aligned}
$$

\section{Extent of Carbonation}

$$
\begin{array}{r}
34.0 \% \\
1.3 \% \\
0.7 \% \\
27.2 \% \\
21.7 \%
\end{array}
$$

\section{Extent of Carbonation Predicted*}

$$
\begin{gathered}
-- \\
-- \\
-- \\
15.4 \% \\
11.5 \%
\end{gathered}
$$

\footnotetext{
* The extent of carbonation predicted is based on a weighting of the extent of carbonation observed for reaction series 1,2 and 3 and the wt $\%$ of these size fractions used in series 4 and 5.
} 
The coarser fractions, $38-75 \mu \& 75-150 \mu$, show almost no carbonation, exhibiting $1.3 \%$ and $0.7 \%$ carbonation, respectively. Importantly, the extent of carbonation observed for the $<75 \mu$ and $<150 \mu$ series are almost double that predicted based on the weighted average of the extents of carbonation observed for the $<38 \mu, 38-75 \mu$ and $75-150 \mu$ size fractions incorporated. Hence, there is significant synergism in terms of particle interactions that can substantially enhance carbonation. For example, if we assume the $38-75 \mu$ and $75-150 \mu$ size fractions remain similarly unreactive, this would translate to $63 \%$ and $68 \%$ carbonation for the $<38 \mu$ fraction in the $<75 \mu$ and $<150 \mu$ runs, respectively. Incorporating quartz as an abrasive agent can also significantly enhance carbonation, underscoring the importance of particle-particle interactions in enhancing carbonation. Controlling the particle size distribution appears to offer intriguing potential to enhance carbonation. We will further explore this potential in Year 2, comparing and contrasting observations for the different flow conditions present in the ARC and ASU reactors.

Scientific Progress: Investigation of the Potential that Sonication Offers to Enhance Exfoliation and Carbonation

Sonication experiments were conducted by stopping the standard mineral carbonation reaction after a half hour, introducing a brief sonication period of 1-10 minutes, followed by a second half hour exposure to the standard mineral carbonation process. The overall carbonation reaction conditions remained the same as the standard carbonation conditions throughout the two halfhour mineral carbonation steps. Extent of carbonation runs that mimic the sonication runs, but without the intermediate sonication exposure, were used for baseline comparison. In each case $15 \mathrm{wt} \%<38 \mu$ San Carlos olivine was mixed with $50 \mathrm{ml}$ of the standard aqueous solution (1M $\mathrm{NaCl}+0.64 \mathrm{M} \mathrm{NaHCO}_{3}$ ) and added to the batch reaction system. After $30 \mathrm{~min}$ of stirred reaction under the standard conditions, the reaction was stopped and rapidly cooled by using the internal cooling coil and placing the reaction vessel in ice water. This results in the temperature dropping to $\sim 40^{\circ} \mathrm{C}$ within $10 \mathrm{~min}$. After cooling is complete, the system is depressurized and the batch reaction stirring system is replaced with the sonication system (Figure 14). The system is purged with $\mathrm{CO}_{2}$ and subsequently brought to the starting sonication temperature and pressure. Once at temperature and pressure, sonication is then run for 1 or $10 \mathrm{~min}$ at full power. Once the sonication is done, the vessel rapidly cooled in ice water and depressurized. The vessel containing the reaction solution is then reattached to the batch reaction system and the second half hour carbonation step is performed.

The extent of carbonation observed for combined $1 / 2$ hour carbonation/sonication/ $1 / 2$ hour carbonation runs is given in Table 4. Under the pressures and temperatures investigated to date, sonication has not enhanced carbonation. Given that the extent of carbonation varies by as much as $\pm 5 \%$ for the same reaction conditions, the results suggest that sonication using the initial conditions explored may even inhibit carbonation. This suggests that high power (1500 watt) sonication exposure may significantly reduce the olivine particle interactions that enhance exfoliation during the second half hour of carbonation. FESEM analysis of the particle size distribution as a function of sonication conditions was initiated at the end of the first project year to explore this effect. Samples taken before and after the sonication step are also being investigated. These studies will be completed in Year 2. As sonication is relatively costly (energy intensive) compared with the other two approaches being investigated (chemical and slurry flow modeling control) and did not show initial promise for low-cost enhancement of 


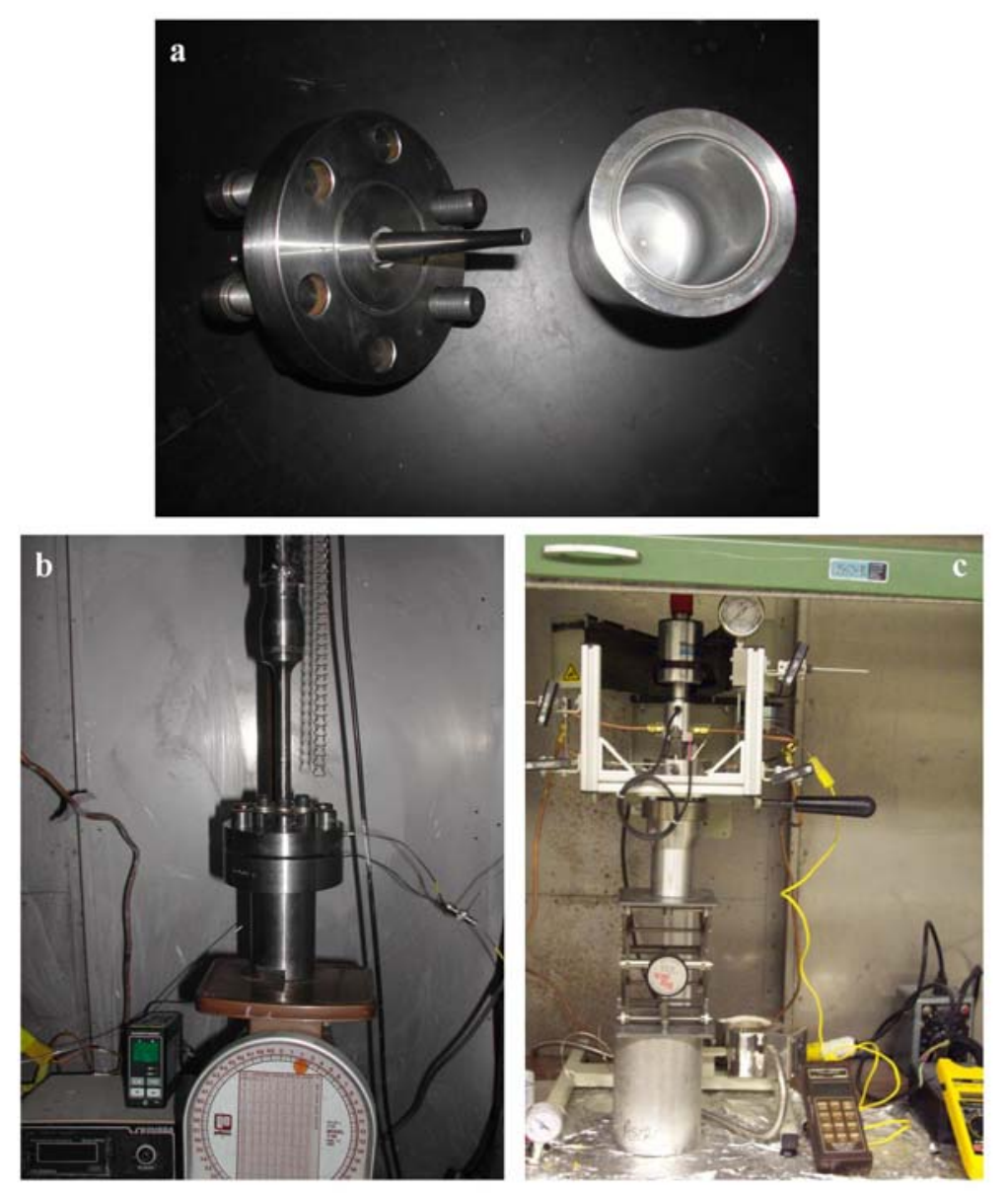

Figure 14. The sonication and batch reaction systems at Arizona State University: (a) The sonication probe and reaction vessel; (b) the reaction vessel sealed to its sonication assembly; (c) the same reaction vessel shown in $a$ and $b$ sealed to the batch reactor stirring assembly.

carbonation, the other two approaches were emphasized during Year 1. We will complete our studies of the effect of temperature, pressure, and sonication power and time on the effectiveness of sonication in enhancing carbonation in Year 2, together with investigations of the effect of fluid composition, and reactant particle concentration and size. If any of the above studies offer hope for low-cost enhanced carbonation, we will investigate combinations of the most effective parameters observed as well.

Scientific Progress: Understanding the Mechanisms that Control Passivating Layer Formation and the Impact the Above Approaches Have on Exfoliation and Carbonation Mechanisms

During the first project year, we have evaluated the effectiveness of a variety of reaction flow dynamics, alkali cation solution chemistry, and sonication approaches to enhance carbonation. These studies have involved carbon elemental analysis and X-ray powder diffraction of scores of product samples. The primary objective in the first project year is to identify those approaches that are most effective in enhancing carbonation. During the first project year, our mechanistic investigations substantially focused on enhancing our understanding of passivation layer structure, composition and behavior associated with the baseline process developed by the ARC. 
Table 4: Effect of sonication on carbonation of San Carlos olivine $(<38 \mu)$. The total carbonation time is 1h.^

\begin{tabular}{|c|c|c|}
\hline Exp. \# & Sonication Conditions & Extent of Carbonation (\%) \\
\hline $132^{\mathrm{B}}$ & $10 \mathrm{~min} ; 20^{\circ} \mathrm{C} ; 900 \mathrm{psi} \mathrm{CO}_{2}$ & 25.9 \\
\hline $202^{\mathrm{D}}$ & $1 \mathrm{~min} ; 20^{\circ} \mathrm{C} ; 15 \mathrm{psi} \mathrm{CO}_{2}$ & 25.4 \\
\hline $203^{\mathrm{D}}$ & $1 \mathrm{~min} ; 20^{\circ} \mathrm{C} ; 900 \mathrm{psi} \mathrm{CO}_{2}$ & 40.0 \\
\hline $207^{\mathrm{D}}$ & $1 \mathrm{~min} ; 20^{\circ} \mathrm{C} ; 2200 \mathrm{psi} \mathrm{CO}_{2}$ & 36.5 \\
\hline $205^{\mathrm{D}}$ & $1 \mathrm{~min} ; 185^{\circ} \mathrm{C} ; 15 \mathrm{psi} \mathrm{CO}_{2}$ & 36.5 \\
\hline $206^{\mathrm{D}}$ & $1 \mathrm{~min} ; 185^{\circ} \mathrm{C} ; 900 \mathrm{psi} \mathrm{CO}_{2}$ & 21.3 \\
\hline $208^{\mathrm{D}}$ & $1 \mathrm{~min} ; 185^{\circ} \mathrm{C} ; 2200 \mathrm{psi} \mathrm{CO}$ & 35.5 \\
\hline $147^{\mathrm{B}, *}$ & none & 39.5 \\
\hline $201^{D^{*}}$ & none & 41.5 \\
\hline $137^{\mathrm{B}, *}$ & none & 34.1 \\
\hline $204^{\mathrm{D}, * *}$ & none & 47.8 \\
\hline
\end{tabular}

"One hour standard runs; ${ }^{* *}$ two half hour runs, $\mathrm{B}=$ olivine batch $\mathrm{B} ; \mathrm{D}=$ olivine batch $\mathrm{D}$

$\wedge$ Note: the temperatures and pressures given are the starting pressures and temperatures associated with sonication. Both T \& P increase significantly during sonication.

The objective is to enhance baseline understanding, while we are exploring in parallel the impact that reaction flow dynamics, alkali cation solution chemistry, and sonication have on exfoliation/carbonation. ${ }^{15}$ In Year 2, we will explore the impact that the approaches that are identified as being most effective in enhancing carbonation have on the mechanisms that govern passivation layer formation, properties, exfoliation, and carbonation reactivity. Substantial progress has been made in enhancing our understanding of passivating layer formation processes during the first year. A summary of the overall understanding developed is given below.

\section{Olivine: A Naturally Occurring Solid Solution Series $\left(\mathrm{Mg}_{\mathrm{x}} \mathrm{Fe}_{1-\mathrm{x}}\right)_{2} \mathrm{SiO}_{4}$.}

Olivine forms a solid solution series between its end members forsterite $\left(\mathrm{Mg}_{2} \mathrm{SiO}_{4}\right)$ and fayalite $\left(\mathrm{Fe}_{2} \mathrm{SiO}_{4}\right)$, with naturally occurring olivine generally richer in magnesium. ${ }^{16}$ It adopts an orthorhombic structure, with $\mathrm{Mg}$ and Fe interchangeably occupying the same lattice sites. The cell parameters generally increase with increasing Fe content, exhibiting Vegard-like behavior between the forsterite and fayalite end members (e.g., $\mathrm{Mg}_{2} \mathrm{SiO}_{4}: \mathrm{a}=4.76 \AA, \mathrm{b}=10.20 \AA$, and $\mathrm{c}=$ $\left.5.98 \AA ; \mathrm{Fe}_{2} \mathrm{SiO}_{4}: \mathrm{a}=4.82 \AA, \mathrm{b}=10.48 \AA, \mathrm{c}=6.11 \AA\right) .{ }^{16}$ The single crystal San Carlos olivine fragments used in the following investigation of the mechanisms that control carbonation at the aqueous solution/olivine reaction interface contain $\sim 8.5 \% \mathrm{Fe}-\left(\mathrm{Mg}_{0.915} \mathrm{Fe}_{0.085}\right)_{2} \mathrm{SiO}_{4}$. 


\section{Investigation of the Carbonation Reaction Products:}

X-ray diffraction (XRD) indicates the products that form during aqueous olivine mineral carbonation are magnesite and amorphous silica, as seen in Figure 15. The only crystalline phases observed are the product magnesite $\left(\mathrm{MgCO}_{3}\right)$ and the unreacted forsterite. The expected

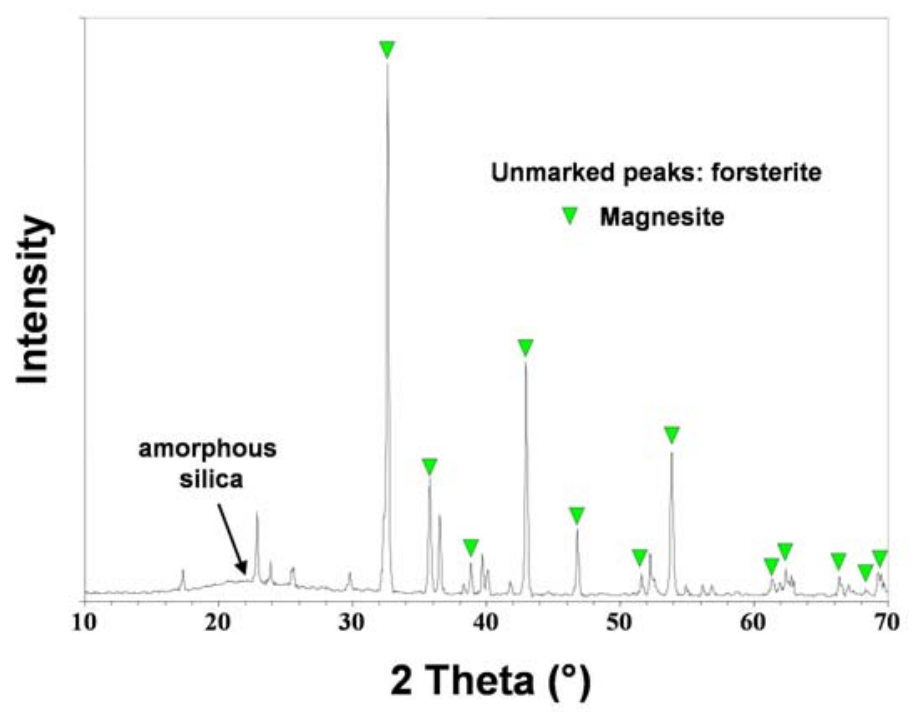

Figure 15. XRD pattern of the aqueous mineral carbonation reaction products showing magnesite, residual forsterite, and the broad increase in scattering intensity centered at $\sim 22^{\circ}$, which is indicative of amorphous silica formation. ${ }^{17}$

silicon-containing product is identified as an amorphous silica-containing material by its characteristic broad scattering intensity around $22^{\circ}{ }^{2}$-theta. ${ }^{17}$ FESEM imaging of the product materials that form during carbonation reveal two characteristic particle shapes, (i) crystals and (ii) irregularly shaped product particles, as shown in Figure 16. The crystals and particles are most frequently observed separately, but a small fraction are intergrown in clusters as well. The morphology of the irregularly shaped particles, as well as the broad XRD intensity around $22^{\circ}$, are consistent with those observed for hydrothermally-formed amorphous silica. ${ }^{17}$ EDS confirms the irregularly shaped particles exhibit the strong $\mathrm{Si}$ and $\mathrm{O}$ signals expected for silica and the polyhedral crystals exhibit the expected strong $\mathrm{Mg}$ and $\mathrm{O}$ signals for magnesite. Elemental analysis of the reaction products shows they do not contain $H$ within experimental error $( \pm 0.3$ $\mathrm{wt} \%$ ), indicating the silica-rich material is largely $\mathrm{H}$ free and primarily associated with siloxane (Si-O-Si) bonding. ${ }^{18}$

A substantial number of the magnesite crystals formed were found to have irregular corners/edges, as seen in Figure 16, indicating particle abrasion accompanies rapidly stirred (1,500 rpm) carbonation. Abrasion can occur via particle-particle interactions and/or particle interactions with the reaction vessel/impeller. Intergrown magnesite/silica clusters typically exhibit preferential magnesite abrasion around the outer cluster edges, indicating the clusters formed during stirred carbonation and not after the reaction stops (Figure 16d). The intimate 

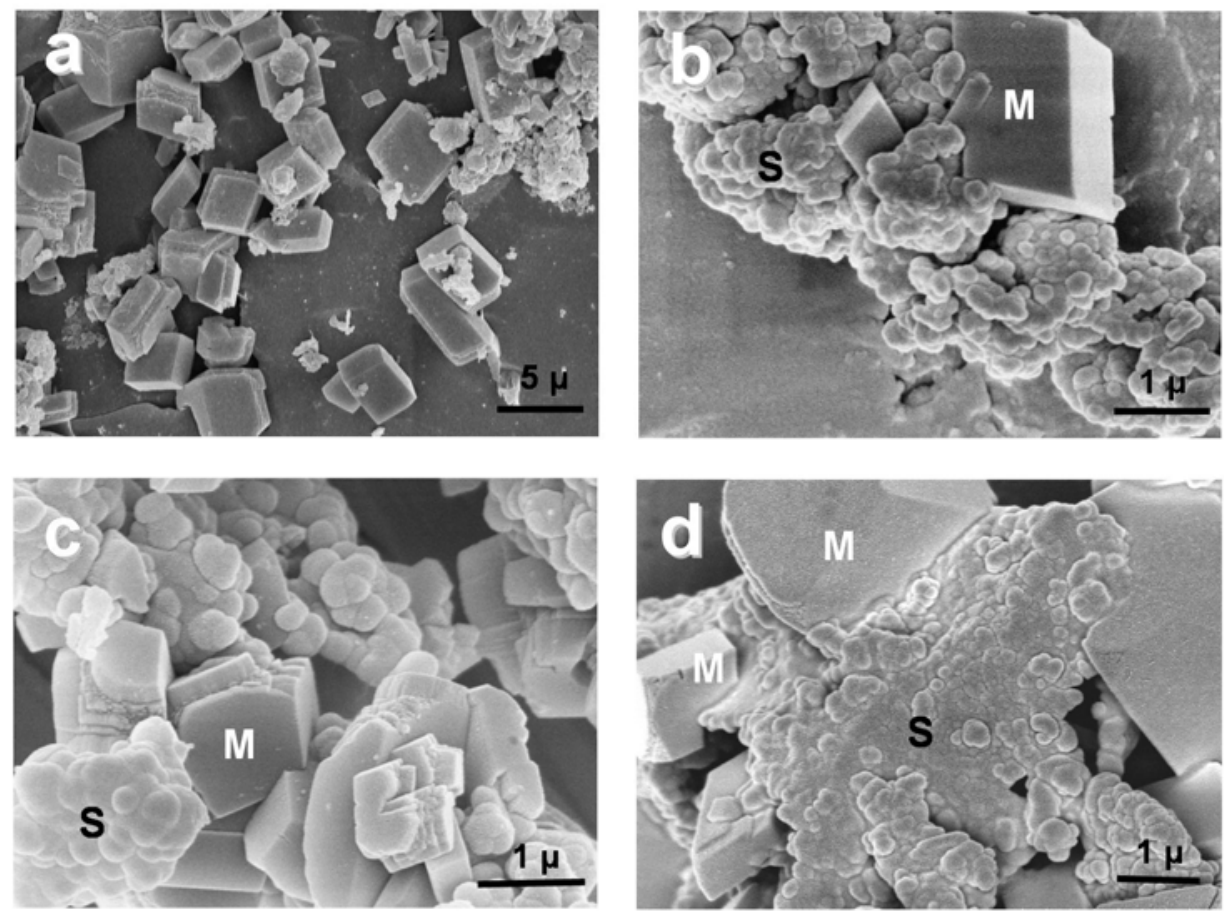

Figure 16. FESEM images of olivine carbonation reaction products. Two types of particles are observed, crystals and irregularly shaped particles. The products are most often observed as separate particles and crystals, but are also observed to have aggregated into clusters during the mineral carbonation process. ( $a$ \& $b$ ) magnesite crystals (M) and irregularly shaped silica-rich particles (S). (c) magnesite crystals with eroded edges and corners are often observed (e.g., the crystal marked "M"), suggesting substantial particle abrasion occurs during carbonation. (d) a close up of an intergrown silica/magnesite composite particle. Selective abrasion of the outer perimeter of the softer magnesite crystals, as observed for the two crystals in the upper left corner (indicated by " $M$ "), indicates the intergrown particles form during carbonation and not as the result of precipitation (see also Figure 20).

intergrowth of silica and magnesite during carbonation indicates that magnesite can nucleate and grow in association with silica formation, as well as directly from solution.

\section{Investigation of the Olivine Reaction Surface/Interface.}

Multiple reactions were stopped before completion to explore representative olivine reaction surfaces/interfaces that form during carbonation and the mechanisms that control reactivity. A few larger $(>200 \mu)$ olivine crystal fragments were added to explore the reaction surface/interface over larger areas. Silica-rich passivating layers and surface regions missing glass-like layer fragments were routinely observed to have formed on the olivine surface during carbonation, indicating passivating layer formation, cracking and exfoliation are integral to the carbonation process, as seen in Figure 17. Figure 17a shows a silica-rich passivating layer region where sections of the layer have fractured and exfoliated. Figure 17b shows a closer view of areas that have experienced passivating layer fracture and exfoliation. In addition to glasslike fracture and exfoliation of original layer fragments, new passivating layer regions have begun to regrow on the olivine surface areas exposed by exfoliation.

A small fraction of the surfaces observed $(\leq 1 \%)$ were largely free of passivating layer formation. 

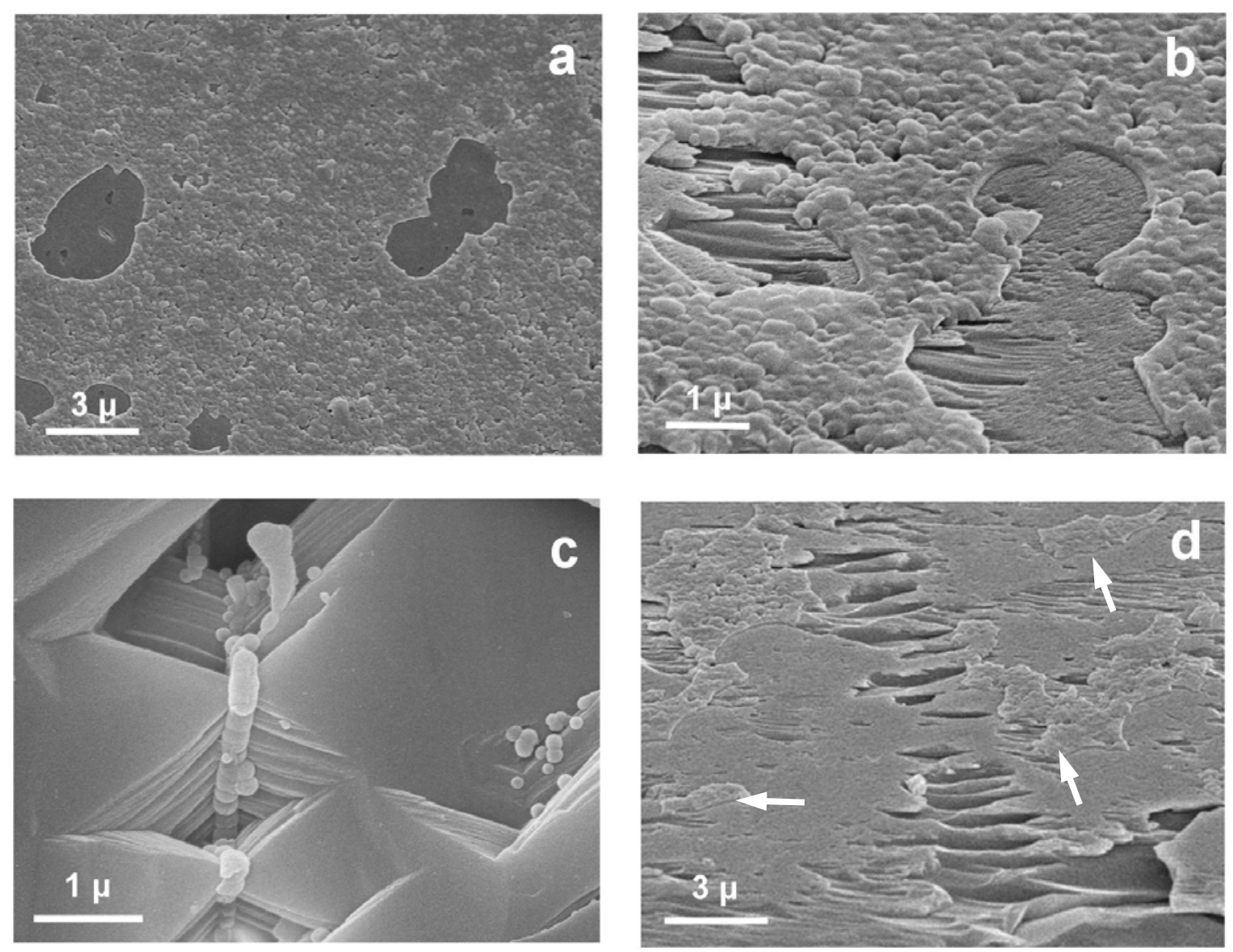

Figure 17. FESEM images of the olivine reaction surface after partial carbonation in the standard aqueous reaction slurry with $1,500 \mathrm{rpm}$ stirring at $185^{\circ} \mathrm{C}$ under $150 \mathrm{~atm} \mathrm{CO}_{2}$. (a) a silica-rich passivating layer that has formed on the olivine reaction surface with areas that have fractured and exfoliated during reaction. (b) a closer view of areas that have experienced passivating layer fracture and exfoliation. Note the regrowth of new passivating layers where the old layer fragments previously exfoliated. (c) Etch pits that formed on the olivine surface during carbonation. Areas in and near the etch pits were often found to be devoid of passivating layer formation. Note the formation of the irregular silica-rich deposits in and on the etch pits, suggesting silica dissolution/precipitation. (d) An area showing regions that have experienced silica-rich passivating layer fracture, exfoliation and regrowth, and regions of fresh olivine surfaces that appear associated with olivine surface defects. Note the apparent olivine fragment that is partially broken away from the surface in the lower right corner. Passivating layer "island" remnants are often found on the reaction surface (indicated by the white arrows)

Surface irregularities, especially etch pits, were generally found in these regions, as shown in Figure 17c. This suggests defects, such as dislocations, inclusions and low-angle grain boundaries, which are commonly found in San Carlos olivine, ${ }^{19}$ can significantly impact local carbonation reactivity by raising the olivine surface energy via strain field formation. This, in turn, can lead to the locally enhanced congruent dissolution observed. Although passivating layers are not typically observed in these regions, irregular silica-rich deposits are occasionally found, suggesting they are largely associated with silica deposition, as seen in Figure 17c. The irregular surface morphology observed for the passivating layers is quite similar to that observed for individual silica particles, as well as for hydrothermally deposited silica, ${ }^{17}$ suggesting silica deposition may also occur on passivating layer surfaces. 
Figure 17d shows a region that has experienced silica-rich passivating layer fracture, exfoliation and regrowth, as well as exposed olivine surfaces. The olivine fragment that appears partially broken away from the surface suggests the exposed olivine surfaces may be associated with the cracking and breaking away of small olivine fragments during carbonation. Several independent passivating layer islands with glass-like fracture edges still remain after the particle has experienced substantial abrasion and layer exfoliation, indicating the layers that form are initially strongly bound to the olivine and associated with incongruent olivine dissolution. Single crystal samples were quenched early during unstirred carbonation to further explore initial passivating layer formation. Cross sectional observation reveals a well-bonded, silica-rich-passivatinglayer/olivine inter-phase interface at the nanoscale, consistent with incongruent dissolution, as seen in Figure 18. Atomic-level high resolution transmission electron microscopy investigations

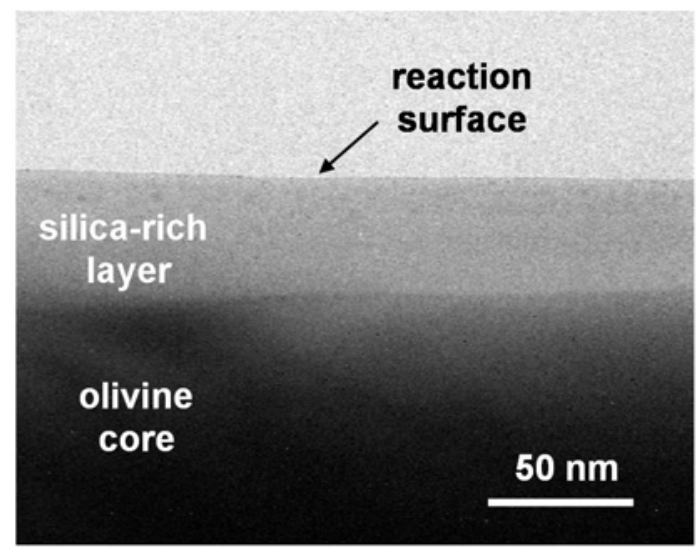

Figure 18. Transmission electron microscope image of a cross section of the silica-rich passivating layer that forms on the olivine surface early in the carbonation process. The sample was prepared under the standard reaction conditions, but without stirring to protect the passivating layer that forms from abrasion. Note the well-bonded interface between the silica-rich passivating layer and the olivine surface.

reveal the interface is well-bonded at the atomic level (see below). Hence, passivating layer formation can be associated with incongruent magnesium dissolution together with some silica deposition from solution on the reaction (e.g., passivating layer) surfaces that form. Interestingly, hydrothermal deposition has been observed to form similarly brittle silica. ${ }^{17}$ The interfacial stress induced at the olivine/silica interface via incongruent olivine dissolution should induce shear forces associated with the reduction in silica volume as olivine is converted to silica at the reaction interface (discussed further below). These forces can further promote the observed fracture and exfoliation of brittle silica passivating layers during stirred carbonation.

Aqueous olivine dissolution is a complex process, with a range of dissolution rates and incongruent as well as congruent dissolution observed as a function of $\mathrm{pH}$ and the presence of anionic species that can impact dissolution at the reaction surface (e.g., chelating agents, such as potassium acid phthalate, KHP). ${ }^{20-23}$ We previously analyzed the aqueous solution equilibrium equations for a $\mathrm{Na}^{+}$buffered $\mathrm{H}_{2} \mathrm{O}-\mathrm{CO}_{2}$ system to explore aqueous speciation and $\mathrm{pH}$ as a function of $\mathrm{T} \& \mathrm{P}$ under mineral carbonation reaction conditions. Similar activities of $\mathrm{CO}_{2}(\mathrm{aq})$ and $\mathrm{HCO}_{3}{ }^{-}$and a $\mathrm{pH}$ of 6-7 were found for the current reaction conditions. ${ }^{24}$ 
A currently accepted picture of olivine acid dissolution is based on the ion exchange reaction $\mathrm{Mg}^{2+} \Leftrightarrow 2 \mathrm{H}^{+}$coupled with the formation of $>\mathrm{SiOH}$ groups. These groups can either form siloxane bonds within the reaction layer via $>\mathrm{Si}-\mathrm{OH}+\mathrm{HO}-\mathrm{Si}<\rightarrow>\mathrm{Si}-\mathrm{O}-\mathrm{Si}<+\mathrm{H}_{2} \mathrm{O}$ (e.g., during incongruent dissolution), or dissolve as $\mathrm{Si}(\mathrm{OH})_{4}$ monomers that can later polymerize and precipitate via analogous siloxane bonding and $\mathrm{H}_{2} \mathrm{O}$ evolution. ${ }^{18,21-23}$ As the silica-containing samples observed herein are largely $\mathrm{H}$-free, it is reasonable to assume that the $>\mathrm{SiOH}$ groups that form during carbonation are transitory, readily succumbing to siloxane bonding to yield the brittle passivating layers observed.

4. Simulation of Passivating Layer Formation: A classical force field approach was applied to investigate the stability, structure and permeability of siloxane passivating layer formation associated with incongruent dissolution. A 12,000 atom model that spans the region from within the olivine to the reaction region at the solution interface was used. The interaction between individual ions is represented by long-ranged coulomb interactions and short-ranged potentials consisting of an exponential repulsion and a van der Waals tail ("Born-Mayer" form).

Classical molecular dynamics simulations were carried out using the MOLDY computer program. ${ }^{25}$ The force fields employed are based on those developed for $\mathrm{MgSiO}_{3}$ by Matsui, ${ }^{26}$ with slightly modified formal charges and Born-Mayer potential parameters for $\mathrm{Mg}$ and $\mathrm{Si}$ chosen to simultaneously reproduce the equations of state of $\alpha$-quartz $\left(\mathrm{SiO}_{2}\right)$ and forsterite $\left(\mathrm{Mg}_{2} \mathrm{SiO}_{4}\right)$. The pair-potential parameters employed are provided in Table 5 along with the effective ionic charges. The simulations of the basic crystalline phases were carried out in a supercell built from $\mathrm{N} \times \mathrm{N} \times \mathrm{N}$ replicas of the respective unit cells (N 3-6). In order to benchmark our procedure we calculated the equilibrium volume of both $\alpha$-quartz $\left(\mathrm{SiO}_{2}\right)$ and forsterite $\left(\mathrm{Mg}_{2} \mathrm{SiO}_{4}\right)$ at $300 \mathrm{~K}$ over a pressure range of -20 to $80 \mathrm{GPa}$. All runs used an integration time

TABLE 5. Born-Mayer Potential Parameters for the Forsterite Simulations. Ionic Charges for O, Mg and Si ions are $-1.365,1.365$ and 2.730 e respectively.

\begin{tabular}{cccc} 
Pair & $\begin{array}{c}\mathbf{A}_{\mathrm{ij}}\left(\mathbf{x 1 0 ^ { - 3 } )}\right. \\
(\mathbf{e V})\end{array}$ & $\begin{array}{c}\mathbf{b}_{\mathrm{ij}} \\
\left(\AA^{-1}\right)\end{array}$ & $\begin{array}{c}\mathbf{C}_{\mathrm{ij}} \\
\left(\mathbf{e V} \AA^{6}\right)\end{array}$ \\
\hline \hline $\mathrm{O}-\mathrm{O}$ & 1.622 & 3.333 & 30.22 \\
$\mathrm{O}-\mathrm{Mg}$ & 8.038 & 4.951 & 0.0 \\
$\mathrm{O}-\mathrm{Si}$ & 7.367 & 5.263 & 0.0 \\
$\mathrm{Mg}-\mathrm{Mg}$ & 1310.1 & 9.615 & 0.0 \\
$\mathrm{Mg}-\mathrm{Si}$ & 2329.2 & 10.870 & 0.0 \\
$\mathrm{Si}-\mathrm{Si}$ & 5008.1 & 12.501 & 0.0
\end{tabular}

step of $0.5 \mathrm{fs}$, velocity rescaling every 10 time steps, and between 10,000-100,000 time steps per run. The energy volume data was fitted to a standard Birch-Murnaghan equation of state form ${ }^{27}$ to extract the equilibrium volume $\left(\mathrm{V}_{0}\right)$ and bulk modulus $\left(\mathrm{B}_{0}\right)$ at ambient pressure. For forsterite we obtained $\mathrm{V}_{0}=69.3 \AA^{3}$ and $\mathrm{B}_{0}=121 \mathrm{GPa}$ (experimental values ${ }^{28}$ : $\mathrm{V}_{0}=72.6 \AA^{3}, \mathrm{~B}_{0}=123 \mathrm{GPa}$ ) while for $\alpha$-quartz we obtained $\mathrm{V}_{0}=39.1 \AA^{3}$ and $\mathrm{B}_{0}=40 \mathrm{GPa}$ (experimental values ${ }^{28}: \mathrm{V}_{0}=37.2 \AA^{3}$, $\mathrm{B}_{0}=37 \mathrm{GPa}$ ). To further calibrate our procedure and test the ability of the pair-potentials to describe amorphous systems we undertook a brief study of silica glass. A structural model was obtained by melting an 648 -atom cell of $\alpha$-quartz and then quenching the structure from $3000 \mathrm{~K}$ by simulated annealing in nine $300 \mathrm{~K}$ cooling stages of $80,000,0.5 \mathrm{fs}$ time steps. The resulting 
structure exhibits all of the hallmarks of thermal glass, including a fully connected corner-shared tetrahedral $\mathrm{SiO}_{4}$ network, and a mean density of about $2.31 \mathrm{~g} / \mathrm{cc}$, which is slightly high compared with the experimental value of $\sim 2.20 \mathrm{~g} / \mathrm{cc}$. To further quantify the bonding distribution of the simulated glass we computed the radial distribution function (RDF) and find that it closely reproduces the essential structure of the RDF observed by neutron scattering for annealed silica glass. $^{29}$

As the dissolution rates associated with passivation-layer (PL) growth via incongruent dissolution are beyond the reach of our simulation times, we devised a synthetic procedure to simulate the low-temperature process. Beginning with a large forsterite slab, we randomly remove $\mathrm{Mg}$ and $\mathrm{O}$ atoms from the outermost region, $10 \AA$ at a time and then carry out a brief relaxation run to re-equilibrate the defective structure without promoting significant $\mathrm{Mg}$ diffusion. We continue this process until $\mathrm{Mg}$ on one half of the full slab is removed. A final annealing run at $500 \mathrm{~K}$ is then performed leading to the diffusion of $\mathrm{Mg}$ and the formation of a reaction interface approximately $20 \AA$ in thickness and an $\sim 50 \AA$ PL with approximately $\mathrm{SiO}_{2}$ stoichiometry, as seen in Figure 19a. Substantial contraction of the newly formed silica region relative to its extent in the olivine framework was observed in the simulated structure. The PL formed consists of a low-density glass-like $\mathrm{SiO}_{2}$ network, with bonding very similar to thermal $\mathrm{SiO}_{2}$ glass (O:Si ratio close to 2). The layer formed is quite stable thermally, remaining essentially unchanged during heating/cooling cycles from $300 \mathrm{~K}$ to $600 \mathrm{~K}$.
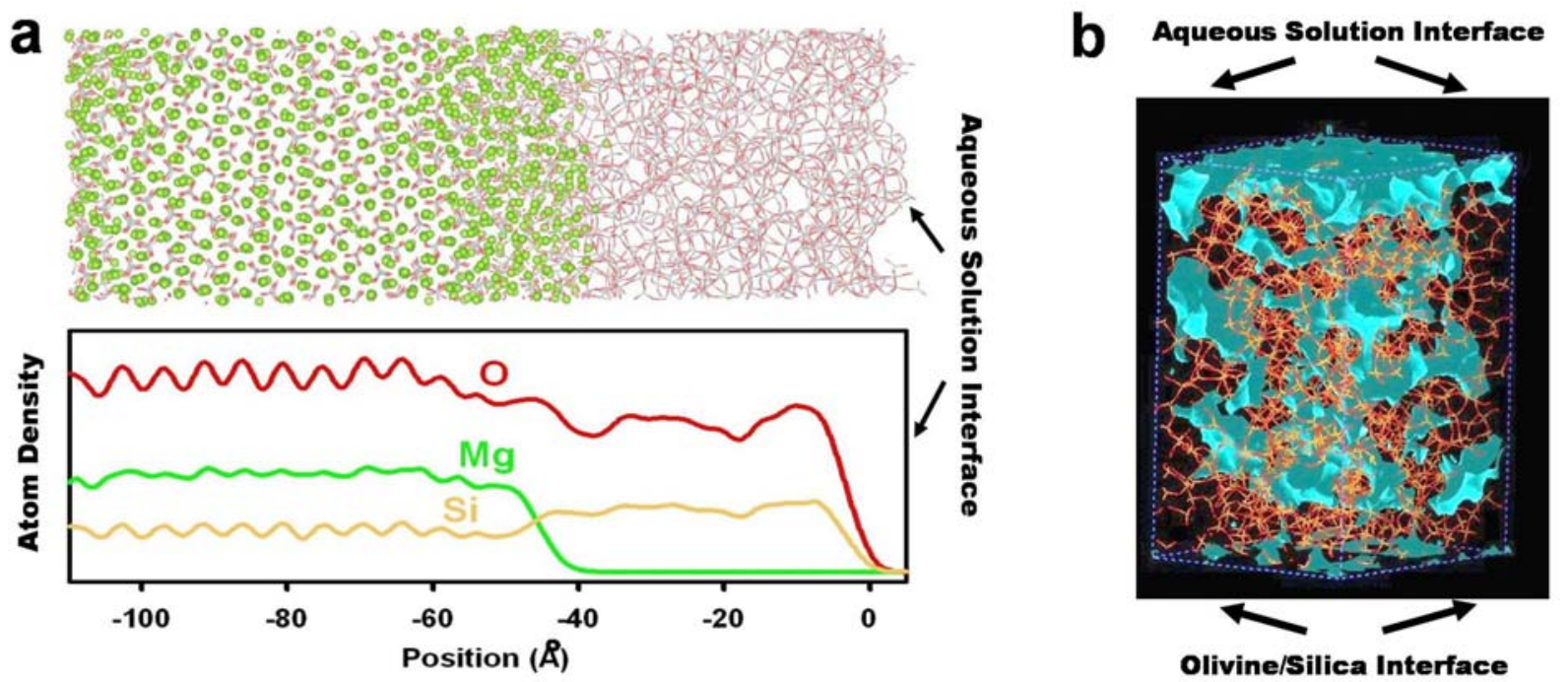

Figure 19. (a) Simulated forsterite/passivation-layer reaction interface system containing 12,000 atoms (above). The associated atom density as a function of distance from the aqueous solution interface is shown below. An $20 \AA$ thick transition layer from $\mathrm{Mg}_{2} \mathrm{SiO}_{4}$ to " $\mathrm{SiO}_{2}$ " is observed. $\mathrm{Mg}, \mathrm{O}$ and Si atoms are represented by green spheres, red sticks and gray sticks, respectively. (b) Map of regions that can accept a $4 \AA$ probe without making van der Waals contact in the silica layer (shown in blue). Note the presence of continuous permeable regions, which can facilitate the diffusion of reactant species in and through the layer.

Layer permeability is critical for PL formation via incongruent dissolution, as it facilitates both the transport of $\mathrm{Mg}$ ions through the layer and the formation of water and its expulsion from the layer. Close examination of the simulated PL structure suggests that even without allowing for the structural disruption associated with $>\mathrm{Si}-\mathrm{OH}$ formation, it may be permeable to key species 
associated with mineral carbonation (e.g., $\mathrm{Mg}^{2+}, \mathrm{H}^{+}$, and $\mathrm{H}_{2} \mathrm{O}$ ), consistent with incongruent dissolution. Such permeability does not exist in our quenched thermal $\mathrm{SiO}_{2}$ glass model, but is found for the simulated PL structures. Interestingly, the RDFs calculated for the simulated $\mathrm{SiO}_{2}$ glass and PL material were found to have significant similarities, suggesting their short-range structure is very similar. ${ }^{30}$ To reveal the differences between the structures we appeal to a "free volume" analysis module available in the Cerius 2 simulation software suite. ${ }^{31}$ The occupiable volume is probed by overlaying grid points set at $0.5 \AA$ intervals throughout the structure. A probe particle is then placed at each grid point in sequence and the point is considered to be "occupiable" if there is no van der Waals contact with the PL structure in any of several hundred directions. Nine probe particles with diameters ranging from $2 \AA$ to $6 \AA$ were used. As expected on the basis of visual inspection and density, the strained PL structure, which retains residual strain as it was relaxed while bonded to the host olivine, exhibits the largest fractional occupiable volume. This is followed by the relaxed PL structure, which is first severed at the olivine interface and then relaxed as above, and thermal glass. About $7 \%$ of the occupiable volume of the strained PL material was found to be able to accommodate $\mathrm{H}_{2} \mathrm{O}$ molecules (Dprobe $\sim 2.8 \AA$ ), ${ }^{32}$ while about $5 \%$ of the volume can accommodate $\mathrm{H}_{2} \mathrm{O}$ in the relaxed PL material (even using the $2 \AA$ probe, the occupiable volume in thermal glass is negligible, as expected). Slightly greater occupiable volumes are expected for $\mathrm{Mg}^{2+}$ owing to its smaller diameter. In order to explore the potential impact of the strained and relaxed PL structures on the diffusion of the species associated with mineral carbonation, the regions of the PL that can accept different probe diameters were mapped out. Their interconnectivity, as illustrated in Figure $19 \mathrm{~b}$, is consistent with reactant species diffusion in/through the PL and incongruent dissolution.

The above simulations and experimental observations point to a passivating layer formation process that is associated with incongruent dissolution and some silica deposition. Both processes apparently involve the acid dissolution of $\mathrm{Mg}^{2+} / \mathrm{Fe}^{2+}$ via the formation of $>\mathrm{Si}-\mathrm{OH}$ groups, which can release $\mathrm{Si}(\mathrm{OH})_{4}$ to solution or undergo condensation reactions prior to dissolution $\left(>\mathrm{Si}-\mathrm{OH}+\mathrm{HO}-\mathrm{Si}<\rightarrow \mathrm{Si}-\mathrm{O}-\mathrm{Si}+\mathrm{H}_{2} \mathrm{O}\right.$ ) to form the siloxane bonds required for incongruent $\mathrm{PL}$ formation. Similar condensation reactions can facilitate $\mathrm{Si}(\mathrm{OH})_{4}$ polymerization and deposition from solution, which can occur on PL surfaces and contribute to PL growth. The presence of strong siloxane bonding within the PLs is evidenced by their brittle fracture and exfoliation.

\section{Intergrowth of Carbonate, Silica and Olivine During Aqueous Carbonation}

Intergrowths of olivine, magnesite and silica were also observed on the surface of partially carbonated particles. The intergrowth on the surface in Figure 20 is generally representative of such particles. Selective erosion of the outside corners of the surface magnesite crystals was routinely observed, indicating (i) significant particle abrasion occurred during carbonation and (ii) the observed olivine/silica/magnesite intergrowth formed during carbonation and not via precipitation or particle settling after the reaction stopped. 


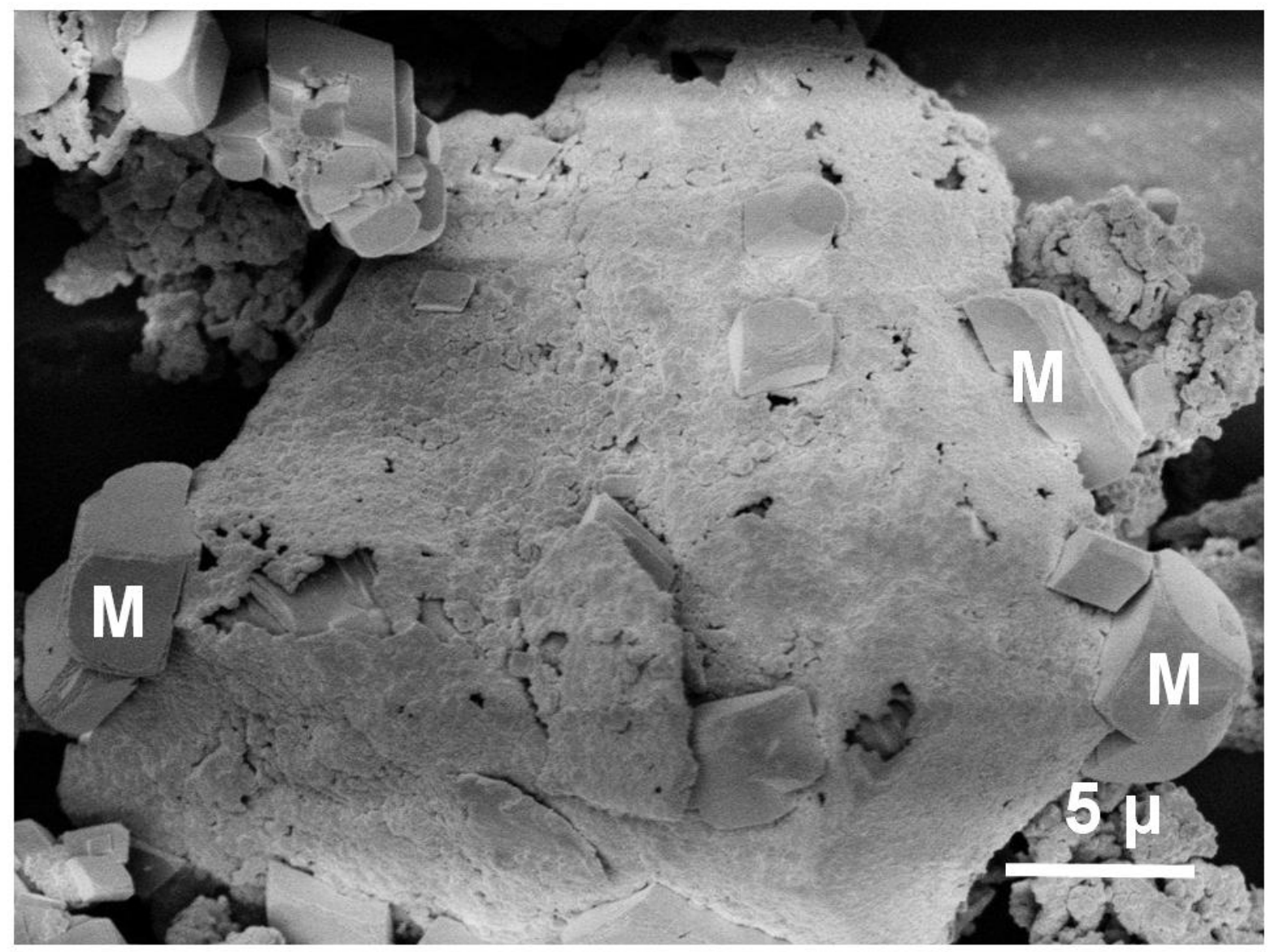

Figure 20. FESEM image of the intergrowth between olivine, amorphous silica and magnesite crystals at the olivine reaction surface. Note the selective appearance of abrasive wear on the outside corners of the magnesite crystals (M) that have grown on the surface of the olivine/silica/magnesite reaction matrix, which indicate the composite particle formed during the 1,500 rpm stirred carbonation reaction and not as the result of precipitation after the reaction and stirring were stopped.

Figure 21 shows FESEM/EDS analysis of the cross section of a similar partially reacted crystal, which illustrates the inward progression of the carbonation reaction from the olivine surface for the stirred mineral carbonation process. The olivine near the reaction layer interface appears structurally disrupted (e.g., cracked) prior to reaction penetration, which may be related to volume contraction of the silica-rich passivating layer that forms via incongruent dissolution at the olivine reaction interface. This observation underscores the key role structural disruption can play in enhancing carbonation reactivity, especially given how effective silica layer formation can be at local reaction passivation. In this case, some magnesite is observed in the silica reaction layer, as evidenced by the separate $\mathrm{Si}$ and $\mathrm{Mg}$ rich regions in the layer observed by EDS. The Mg and Fe maps demonstrate a strong correlation between $\mathrm{Mg}$ and Fe both in the olivine feedstock and product magnesite in the reaction layer, indicating both the $\mathrm{Mg}$ and $\mathrm{Fe}$ are transported into the product carbonate during carbonation. The silica regions observed are essentially Fe free. 

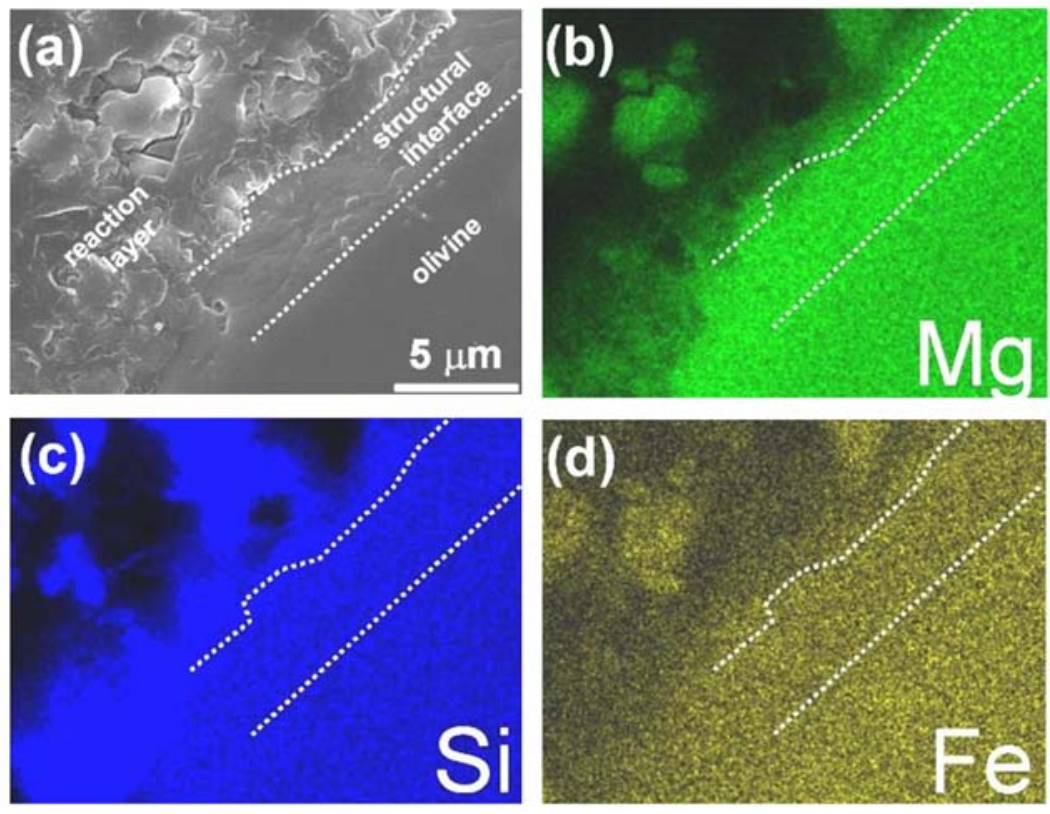

Figure 21. a) FESEM secondary electron image of a cross-section of a partially carbonated olivine single crystal showing structural disruption of the olivine preceding the mineral carbonation process as the reaction front penetrates to the crystal interior. The crystal surface is in the upper left corner. b-d) Mg, Si, and Fe EDS maps of the reaction interface cross section.

\section{Controlled Particle Abrasion: Enhancing Passivating Layer Exfoliation and Carbonation.}

Silica-rich passivating layer formation during mineral carbonation clearly has the potential to substantially inhibit carbonation reactivity. However, the layers that form are brittle, strained and susceptible to fracture and exfoliation that can expose fresh olivine surfaces that enhance reactivity. Hence, particle interactions may be expected to significantly enhance carbonation reactivity. To probe the potential that particle-particle interactions (abrasion) offer to erode passivating layers as they form and enhance carbonation reactivity, we investigated the extent of carbonation observed as a function of wt.\% forsterite for stirred $(1,500 \mathrm{rpm})$ carbonation, as seen in Figure 22. The systematic increase in the extent of carbonation with increasing wt.\% forsterite (particle concentration) demonstrates the importance of particle-particle interactions (abrasion) in exposing fresh olivine reaction surfaces and enhancing carbonation reactivity. In recent simulations of colliding monodisperse spheres in forced isotopic turbulent flow, corresponding closely to the stirred tank conditions in our experiments, Derksen et al. ${ }^{33}$ identified two distinct collision mechanisms: (i) primary collisions consisting of uncorrelated "kinetic gas"-like random contacts and (ii) highly correlated secondary collision processes, involving a repetitive "chattering" motion on a short time scale, due to short-range hydrodynamic effects (lubricating forces). Elementary geometric considerations deliver a length scale (L) dependence on weight $\%$ solids, $\mathrm{W}$, proportional to $\mathrm{W}^{-1 / 3}$. The removal rate of PL material, $R_{P L}$, is therefore proportional to $V_{\text {avg }} / \mathrm{L}=\mathrm{AW}^{1 / 3}$, where $V_{\text {avg }}$ is the mean relative velocity between a pair of particles and $A$ is a constant. If we assume that the diffusion of reactants through the $\mathrm{PL}$ is rate-limiting, and that 


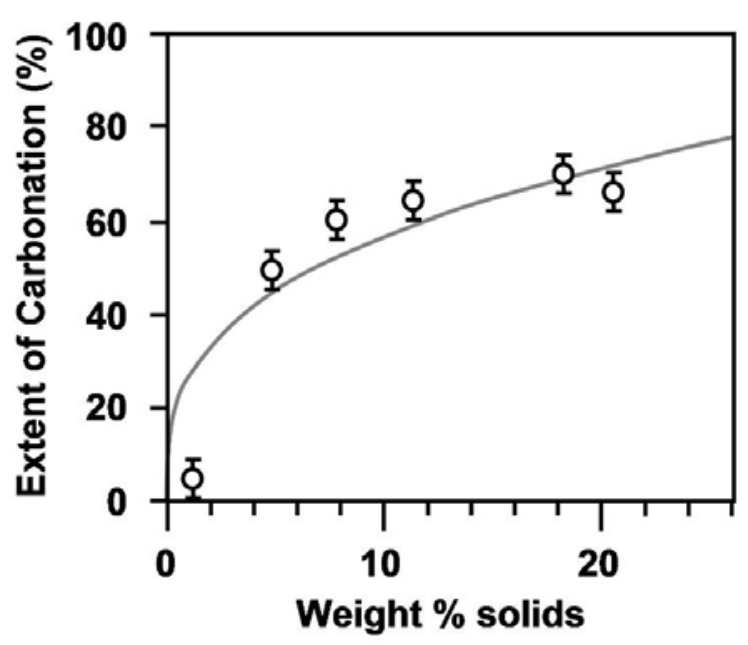

Figure 22. Plot of the extent of carbonation observed as a function of weight $\%$ forsterite used in the aqueous carbonation solution $(0.64 \mathrm{M} \mathrm{NaHCO} 3+1.00 \mathrm{M} \mathrm{NaCl})$ at $1,500 \mathrm{rpm}\left(185{ }^{\circ} \mathrm{C} ; 150\right.$ bar $\left.\mathrm{CO}_{2} ; 1 \mathrm{hr}\right)$. The error bars shown represent the standard deviation typically observed for multiple runs under the same reaction conditions. The grey line is a fit to the form $A W^{1 / 3}$, where A 26.2. Note: The fit is not expected to continue for higher weight $\%$ solids where other contributing factors, such as particle-particle agglomeration, will eventually become substantial and reduce PL exfoliation and carbonation.

complete passivation occurs in a time $T_{0}$ in an unstirred setting, then the extent of carbonation is proportional to $T_{R U N} R_{P L} \propto \mathrm{W}^{1 / 3}$ where $T_{R U N}>T_{0}$ is the duration of the stirred reaction experiment. This dependence on weight \% solids is illustrated in Figure 22, where a best fit yields a proportionality constant of about 26.2, a value much larger than expected based on the presence of primary collisions alone. The large coefficient may be explained by a high frequency of secondary collision processes.

We have recently discovered that the inclusion of abrasive particles (e.g., quartz) can further enhance olivine carbonation, providing additional evidence for the importance of particle abrasion. Clearly, olivine carbonation reactivity can be substantially improved by enhancing abrasion. Controlling abrasion during in situ carbonation may also allow the effective use of larger olivine feedstock particle sizes, as discussed previously. This would substantially lower the cost of feedstock preparation, as the vast majority of the cost in grinding the olivine feedstock to $<37$ microns is associated with particle-size reduction from $<75$ to $<37$ microns. $^{8}$

\section{Passivating Layer Formation during Unstirred Carbonation.}

Single crystal samples with surface normal [010] were reacted using the standard aqueous mineral carbonation process developed by the Albany Research Center, but without stirring, to avoid the effects of particle-particle and particle-system abrasion. The resulting reaction surface and interface with the olivine substrate were investigated via scanning and transmission electron microscopy. The reacted olivine surface after $4 \mathrm{hrs}$ is shown in Figure 23. Stereographic SEM imaging shows the as-reacted surface (after multiple $\mathrm{H}_{2} \mathrm{O}$ rinses to remove soluble salts) to be covered with a buckled silica-rich passivating layer, with the buckling extending upward away from the substrate. Sonication in water after reaction removed the buckled regions, which were 

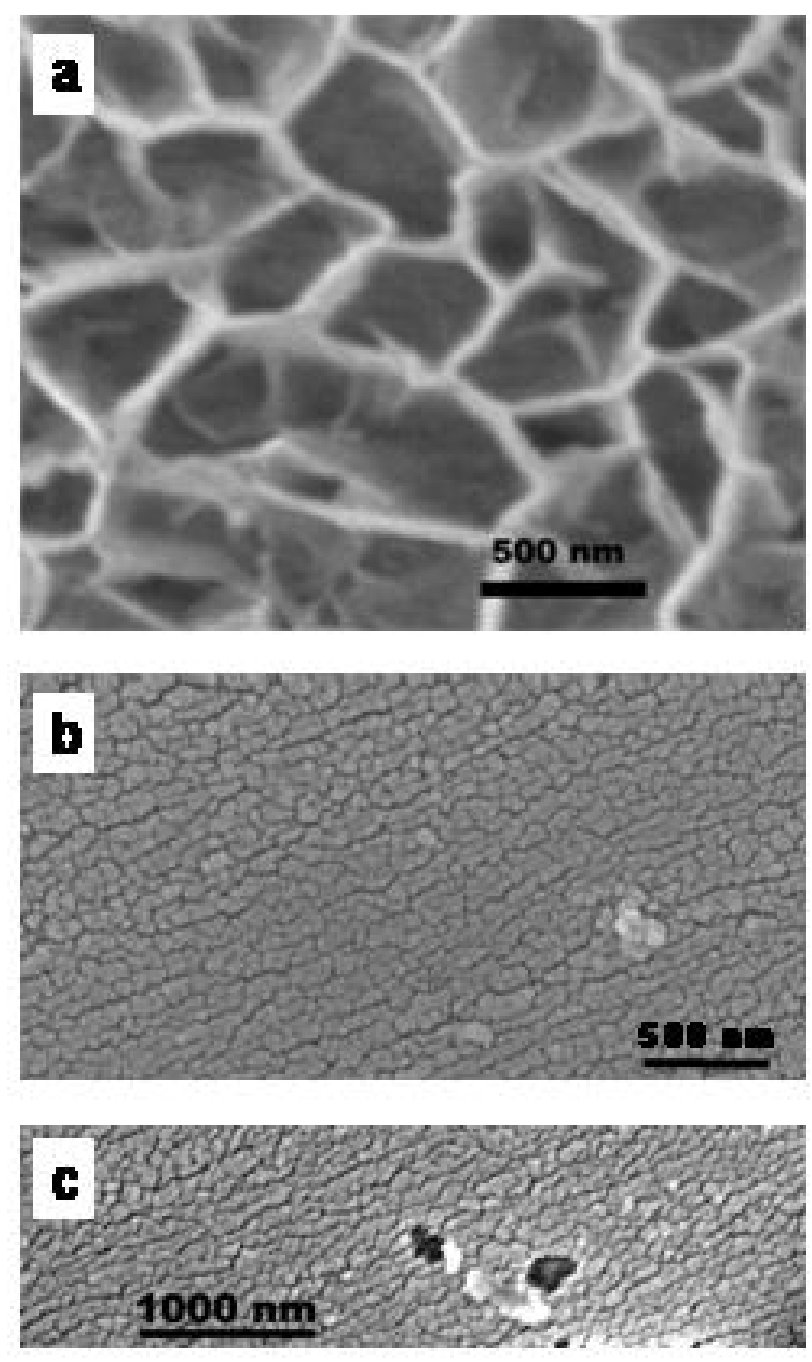

Figure 23. SEM images of reacted olivine surfaces. surface normal $=[010]$. Reaction conditions: 150 bar $\mathrm{CO}_{2}$, $185{ }^{\circ} \mathrm{C}$ and 4hrs. (a) cleaned surface after reaction exhibited debonded high $\mathrm{SiO}_{x}$ content reaction layers. (b) cleaned and sonicated reacted surface showing well bonded high $\mathrm{SiO}_{x}$ reaction layer islands separated by cracks. (c) Islands that debonded during sonication via interfacial cracking.

not strongly bonded to the substrate, and revealed the underlying cracks in the passivating layer shown in Figure 23b. Energy dispersive x-ray nanospectroscopy showed that the RL "islands" that remained bonded to the substrate had high $\mathrm{Si}$ and $\mathrm{O}$ content relative to the bottom of the cracks, where the composition corresponded to olivine. The bottom of the cracks were thus high reactivity sites. The average size of the bonded islands was $\sim 100 \mathrm{~nm}$, and the crack width between islands was $\sim 20 \mathrm{~nm}$. Fig. 23c shows sonication can dislodge a small number of RL islands that became partially debonded during the reaction. The area under these was bare olivine or a very thin passivating layer.

Figure 24a shows a cross section HREM image of a passivating layer island at its interface with the olivine substrate, showing a typically well-bonded inter-phase interface boundary indicating incongruent magnesium dissolution substantially contributes to passivating layer formation. 

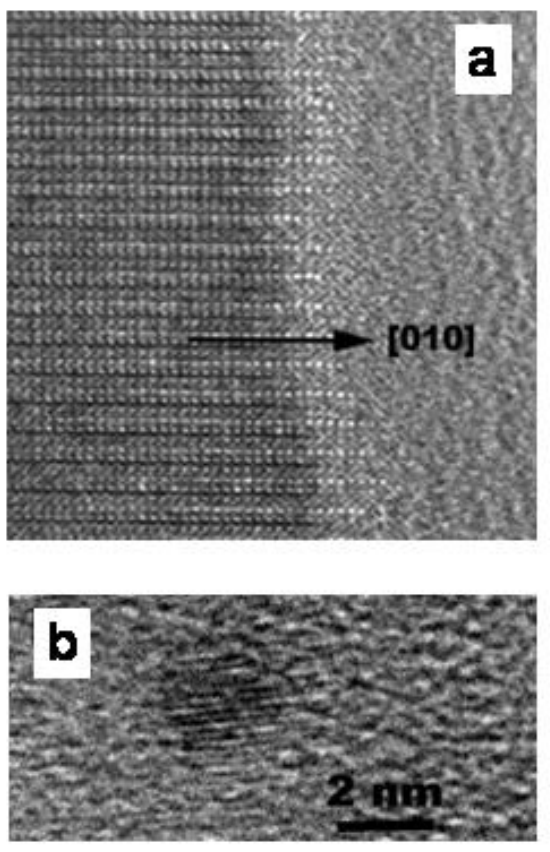

Figure 24. TEM images of reacted olivine. $200 \mathrm{keV}$. (a) Cross section image of the olivine/PL interface. The passivating layer $(P L)$ is amorphous. The transition across the olivine/PL boundary is not sharp, and should correspond to a steep [MgO] gradient, as predicted in Figure 19. (b) A typical $\mathrm{MgCO}_{3}$ nanoparticle observed in the silica-rich passivating layer.

The passivating layer region was amorphous on all specimens examined. Its interface with the olivine illustrates the transition from crystalline olivine to the amorphous silica-rich passivating layer is not structurally sharp. The passivating layers contain a distribution of randomly oriented crystalline nanoparticles (Figure $24 \mathrm{~b}$ ), which were identified as magnesite $\left(\mathrm{MgCO}_{3}\right)$ or periclase $(\mathrm{MgO})$ via image analysis and FFT diffraction. As magnesite is well known to be extremely electron beam sensitive, ${ }^{34}$ readily decomposing to periclase in the process, we conducted radiation effects experiments on both nanoparticle and bulk $\mathrm{MgCO}_{3}$. These studies confirmed that magnesite, especially the magnesite nanocrystals present in the passivating layers, is very sensitive to both electron irradiation effects during HREM observation/analysis and ion beam damage during specimen preparation. Both processes readily cause decomposition to $\mathrm{MgO}$, consistent with earlier electron irradiation observations made on bulk $\mathrm{MgCO}_{3}{ }^{34}$ Thus, the nanoparticles that formed during carbonation were $\mathrm{MgCO}_{3}$. The $\mathrm{MgO}$ particles observed are artifacts formed by $\mathrm{MgCO}_{3}$ decomposition during specimen preparation or electron beam observation. This intriguing observation indicates that the passivating layers that form are not only permeable to $\mathrm{Mg}^{2+}, \mathrm{H}^{+}$, and $\mathrm{H}_{2} \mathrm{O}$ associated with magnesium dissolution during the carbonation process, they are also permeable to the species responsible for carbonation (e.g., $\mathrm{CO}_{2}(\mathrm{aq}), \mathrm{CO}_{3}{ }^{2-}, \mathrm{HCO}_{3}{ }^{-}$). It is interesting to note that the interconnected occupiable volumes within the simulated passivating layer shown in Figure 19 can also support substantial $\mathrm{CO}_{2}$, $\mathrm{CO}_{3}{ }^{2-}$, and/or $\mathrm{HCO}_{3}{ }^{-}$diffusion, consistent with the observed intralayer nanocrystal magnesite formation. 
The average nanoparticle size was about $6 \mathrm{~nm}$, and the particle volume fraction in the passivating layer was calculated to be $\approx 0.13$, using TEM methods. ${ }^{35-37}$ If the carbonation reaction proceeded simply by forming a mixture of magnesite and $\mathrm{SiO}_{\mathrm{x}}$ on the olivine, the magnesite volume fraction in the passivating layer would have been much larger. The molar volumes of the reactants and products $\left(\mathrm{V}_{\mathrm{M}}\right.$ for olivine and magnesite are 43.6 and $28.0 \mathrm{cc} / \mathrm{mol}$ respectively, ${ }^{38}$ and $\approx 26 \mathrm{cc} / \mathrm{mol}$ for $\mathrm{SiO}_{\mathrm{x}}{ }^{39}$ ) can be used to show that the magnesite volume fraction in the passivating layer would have been about 0.68. The much smaller magnesite fraction observed within the passivating layer indicates that most of it formed external to the layer (e.g., in the aqueous solution itself).

The interfacial bond between the olivine and the silica-rich passivating layer results in a strain gradient across the island thickness that induces bending moments in the film and peeling stresses at the interface. ${ }^{40,41}$ These moments and stresses are largest at the PL island edges, and can contribute to crack propagation along the PL/olivine interface and peeling of the PL upward away from the substrate, ultimately resulting in the islands detaching from the olivine substrate. The surface observed in Figure 23a is consistent with debonded peeling PL, with the structures observed easily removed from the reacted specimen surface by sonication. Other examples of PL island debonding are visible in the middle of Figure 23c; these regions probably had partially cracked interfaces before sonication. The height of the structures observed in Figure 23a may well also be associated with local silica dissolution precipitation, with the structures growing away from the reaction interface into the solution.

\section{Molecular Dynamics Simulations of Reactant Solutions}

During the first year of the performance period we also initiated modeling studies of the standard aqueous reactant solution $\left(\mathrm{NaCl} / \mathrm{NaHCO}_{3}\right.$ buffered $\left.\mathrm{H}_{2} \mathrm{O}+\mathrm{scCO}_{2}\right)$, beginning with the thermodynamic simulation of the $\mathrm{H}_{2} \mathrm{O}+\mathrm{scCO}_{2}$ system, as the reaction solution incorporated was found to have a dramatic impact on carbonation reactivity. Our equilibrium classical molecular dynamics simulations of the reactant solutions at various $\mathrm{P}$ and $\mathrm{T}$ are based on the COMPASS force field, ${ }^{42}$ which has been exhaustively validated using a broad range of aqueous systems. However, because our work involves an excursion into the supercritical phase region of $\mathrm{CO}_{2}$, where experimental data is scarce and validation has not been carried out, the results should be viewed as preliminary pending detailed benchmarking against results of $a b$ initio simulation. As experimental information about the $\mathrm{H}_{2} \mathrm{O}-\mathrm{CO}_{2}-\mathrm{NaCl}-\mathrm{NaHCO}_{3}$ system at $\mathrm{T} \sim 185{ }^{\circ} \mathrm{C}$ and $\mathrm{P}_{\mathrm{CO} 2} \sim 150$ bar becomes available through our related work in other projects it will be used to tune the empirical parameters in our classical simulations and further validate our approach. Here we summarize our preliminary results.

The aqueous solutions were modeled using between 100 and 160 water molecules. $\mathrm{CO}_{2}$ molecules were then added on the basis of $\mathrm{CO}_{2}$ solubility data which has recently been accurately fitted to an analytic model by Duan and Sun. ${ }^{43}$ The thermodynamic data indicates that $\mathrm{CO}_{2}$ solubility generally decreases with increasing temperature, and increases with increasing $\mathrm{CO}_{2}$ pressure. Typical values for our experimental conditions are between 0.1-1.2M $\mathrm{CO}_{2}$, with the higher values corresponding to our reaction conditions $\left(\mathrm{T} \sim 185{ }^{\circ} \mathrm{C}, \mathrm{P}_{\mathrm{CO} 2} \sim 150 \mathrm{bar}\right)$. The initial structure of the water was generated by placing $\mathrm{H}_{2} \mathrm{O}$ molecules on a grid corresponding to a volume of $30 \AA^{3}$ per molecule. The system was then relaxed using a simulated annealing 
procedure to a static lattice energy minimum. Thermodynamic simulations were then undertaken using an NPT (constant number of particles: N, pressure: P, and temperature: $\mathrm{T}$ ) ensemble in which $\mathrm{P}$ and $\mathrm{T}$ are specified to match either STP or our reaction conditions, with a 1 fs integration time step. Equilibration typically required about $40 \mathrm{ps}$ (corresponding to 40,000 molecular dynamics steps). To calculate correlation functions and other properties we then carried out additional simulations in the NVE (constant number of particles: N, volume: V, and temperature: T) ensemble using 20,000 MD steps, using the final average densities and configurations from the NPT simulations. This approach produced low RMS fluctuations and accurate statistics for the ensemble averages.

To simulate the more complex $\mathrm{NaCl}-\mathrm{H}_{2} \mathrm{O}-\mathrm{CO}_{2}$ solutions we simply incorporated $\mathrm{NaCl}$ into the computational cells at the required concentrations. At STP a $1 \mathrm{M} \mathrm{NaCl}$ solution consists of approximately $1 \mathrm{Na}+\mathrm{Cl}$ pair for every 55 water molecules. In order to keep our simulations consistent with our experiments we appealed to the Sun et al equation to determine the solubility of $\mathrm{CO}_{2}$ in $\mathrm{NaCl}$ buffered $\mathrm{H}_{2} \mathrm{O}$. In general the addition of $\mathrm{NaCl}$ significantly suppresses the solubility of $\mathrm{CO}_{2}$ (about a factor of 2 in going from pure water to a $2 \mathrm{M} \mathrm{NaCl}$ aqueous solution). ${ }^{43}$ Initial results of our simulation studies are presented in Table 6, which lists the simulated total energies and provides a comparison of simulated molar volumes with those

Table 6: Total energy (E) and molar volumes $(\Omega)$ of aqueous solutions obtained from a NPT ensemble simulation followed by a 10 ps NVE simulation. Experimental values from Ref. 44. Asterisks are values for pure water, used here as a proxy for comparison with the actual reactant solution.

\begin{tabular}{|l|c|c|c|c|c|}
\hline \multicolumn{1}{|c|}{ System } & $P($ bar $)$ & $\left.T{ }^{\rho} \mathrm{C}\right)$ & $E(\mathrm{kcal} / \mathrm{mol})$ & $\Omega_{S I M}(\mathrm{cc} / \mathrm{mol})$ & $\Omega_{E X X}^{H 2 O}(\mathrm{cc} / \mathrm{mol})$ \\
\hline Pure $\mathrm{H} 2 \mathrm{O}$ & 1 & 25 & -575.5 & 18.3 & 18.1 \\
\hline $1 \mathrm{M} \mathrm{CO}_{2}$ in $\mathrm{H}_{2} \mathrm{O}$ & 1 & 25 & -571.5 & 18.4 & $18.1^{*}$ \\
\hline $1 \mathrm{M} \mathrm{CO}_{2}$ in $\mathrm{H}_{2} \mathrm{O}$ & 150 & 185 & -154.2 & 22.2 & $20.6^{*}$ \\
\hline $1 \mathrm{M} \mathrm{CO}_{2}+1 \mathrm{M} \mathrm{NaCl}$ in $\mathrm{H}_{2} \mathrm{O}$ & 1 & 25 & -731.0 & 19.0 & $18.1^{*}$ \\
\hline $1 \mathrm{M} \mathrm{CO}_{2}+1 \mathrm{M} \mathrm{NaCl}$ in $\mathrm{H}_{2} \mathrm{O}$ & 150 & 185 & -290.5 & 28.9 & $20.6^{*}$
\end{tabular}

obtained experimentally for pure water. For $\mathrm{H}_{2} \mathrm{O}-\mathrm{CO}_{2}$ solutions predicted densities are in reasonable agreement with experiment, exhibiting a slight volume overestimate particularly at high pressures. Unfortunately, experimental molar volume data for the $\mathrm{NaCl}-\mathrm{H}_{2} \mathrm{O}-\mathrm{CO}_{2}$ solution has not been reported at the reaction conditions. For a $1 \mathrm{M} \mathrm{CO}_{2}+1 \mathrm{M} \mathrm{NaCl}$ in $\mathrm{H}_{2} \mathrm{O}$ solution at $\mathrm{T}$ $=185^{\circ} \mathrm{C}$ and $\mathrm{P}_{\mathrm{CO} 2}=150$ bar, our simulations predict $\mathrm{a} \sim 50 \%$ increase in molar volume relative to STP. This is significantly greater than the corresponding molar increase in the $\mathrm{H}_{2} \mathrm{O}-\mathrm{CO}_{2}$ system for the same conditions.

Understanding of hydrated ions as a function of temperature and pressure is fragmented and incomplete, and molecular dynamics simulations can provide direct information about atomic motion at the reaction conditions of interest. Therefore, to elucidate the origin of the concentration, temperature and $\mathrm{P}_{\mathrm{CO} 2}$ dependences in our carbonation experiments we calculated the diffusivity constants and solvation structures of all species in the reactant solution. This represents the first step in determining the importance and individual roles of various carbonaceous species $\left(\mathrm{CO}_{2}(\mathrm{aq}), \mathrm{CO}_{3}{ }^{2-}, \mathrm{HCO}_{3}{ }^{-}, \mathrm{H}_{2} \mathrm{CO}_{3}{ }^{*}\right)$. Figure 25 shows a snapshot of the structure of the hydration shell surrounding the solutes $\mathrm{Na}^{+}, \mathrm{Cl}^{-}$and $\mathrm{CO}_{2}$ at the simulated reaction conditions $\left(\mathrm{T}=185{ }^{\circ} \mathrm{C}, \mathrm{P}_{\mathrm{CO} 2}=150 \mathrm{bar}\right)$. Integration of the pair-correlation functions yields 

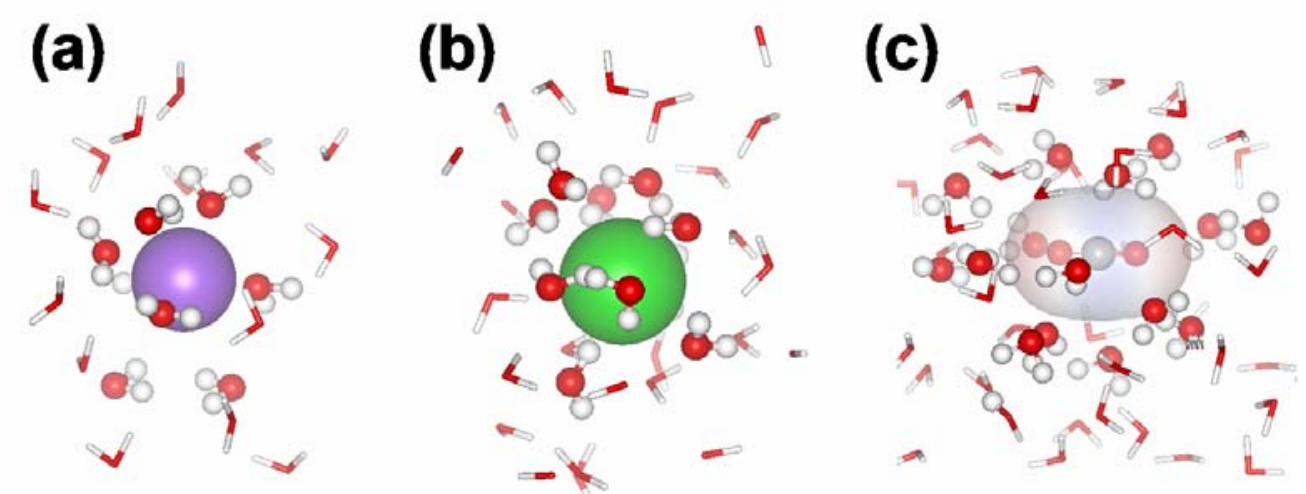

Figure 25: Snapshots of the hydration shell structure in $1 \mathrm{M} \mathrm{CO}_{2}+1 \mathrm{M} \mathrm{NaCl}+\mathrm{H}_{2} \mathrm{O}$ at $\mathrm{T}=185{ }^{\circ} \mathrm{C}$ and $\mathrm{P}_{\mathrm{CO} 2}=150$ bar: (a) sodium ion surrounded by $\mathrm{H}_{2} \mathrm{O}$ molecules oriented with oxygen inward, (b) chloride hydration structure showing $\mathrm{H}_{2} \mathrm{O}$ protons oriented inward, (c) hydration structure surrounding the $\mathrm{CO}_{2}$ molecule (faded surface is a superposition of vdW radii). Inner hydration shell water molecules are shown as ball-stick for emphasis. From pair-correlation analysis the coordination numbers are 5.5, 6.5 and 9.1 for $\mathrm{Na}^{+}, \mathrm{Cl}^{-}$and $\mathrm{CO}_{2}$, respectively.

coordination numbers 5.9, 7.2 and 9.1 for $\mathrm{Na}^{+}, \mathrm{Cl}^{-}$and $\mathrm{CO}_{2}$, respectively. These values are very similar to those obtained at ambient conditions (5.6, 6.8 and 8.7) indicating that solute coordination is relatively weak function of pressure and temperature in these systems. One of the properties expected to play an important role in reactivity dependence on $\mathrm{T}$ and $\mathrm{P}$ is the translational self-diffusion. This is because the relative diffusivity of carbon bearing reactants in comparison to solvent and other reactant species, such as $\mathrm{Mg}^{2+}$, is directly related to the reaction rate. Enhanced reaction is expected at $\mathrm{P}_{\mathrm{CO} 2}$ and $\mathrm{T}$ conditions which increase the diffusivity of all reactants in the solution. Our objective is to explore this dependence via simulation. The selfdiffusion coefficient can be obtained from the long-time behavior of the mean-square displacements via

$$
D=\operatorname{Lim}_{t \rightarrow \infty} \frac{\left\langle[R(t)-R(0)]^{2}\right\rangle}{6 t}
$$

To calculate this property we equilibrated the systems using 50,000 time steps in the NPT ensemble and then collected trajectory data for an additional 50,000 steps in the NVE. Typically the slope of the function (1) was evaluated using the last 20,000 steps. Our results are presented in Table 7 which lists the diffusion coefficients for a range of systems at STP and at reaction conditions. At ambient conditions we find that the addition of $\mathrm{CO}_{2}\left(1 \mathrm{M} \mathrm{CO}_{2}\right.$ was chosen for simplicity) has a negligible effect on $\mathrm{H}_{2} \mathrm{O}$ self-diffusivity and that the diffusion coefficient of $\mathrm{CO}_{2}$ is slightly larger than that of water. Our simulations show that the addition of $\mathrm{NaCl}$ reduces the self diffusivities of $\mathrm{H}_{2} \mathrm{O}$ by more than half, in agreement with the results of recent calculations for $\mathrm{NaCl}+\mathrm{H}_{2} \mathrm{O}$ solutions. ${ }^{45}$ This suppression is alleviated by increasing $\mathrm{P}_{\mathrm{CO} 2}$ and temperature, as can be seen from the tabulated data, which indicates an order of magnitude increase in $\mathrm{H}_{2} \mathrm{O}$ self-diffusion and a factor of $\sim 2$ increase in $\mathrm{CO}_{2}$ self-diffusion at $\mathrm{T}=185{ }^{\circ} \mathrm{C}$ and $\mathrm{P}_{\mathrm{CO} 2}=150$ bar. Another significant finding is that the self-diffusivity of $\mathrm{Na}^{+}$ions is systematically higher than that of their $\mathrm{Cl}^{-}$anion counterparts under these conditions. In fact, at these conditions the self-diffusivity of $\mathrm{Na}^{+}$and $\mathrm{CO}_{2}$ is found to be comparable and this may have 
Table 7: Translational self-diffusion coefficients, in units of $10^{-5} \mathrm{~cm}^{2} / \mathrm{s}$, for $\mathrm{H}_{2} \mathrm{O}, \mathrm{CO}_{2}, \mathrm{Na}^{+}$and $\mathrm{Cl}^{-}$for a range of aqueous solutions. The experimental value for $\mathrm{H}_{2} \mathrm{O}$ self-diffusion at STP is $2.5 \times 10^{-5} \mathrm{~cm}^{2} / \mathrm{s}$.

\begin{tabular}{|c|c|c|c|}
\hline System & $\begin{array}{c}\text { Diffusing } \\
\text { Species }\end{array}$ & $\begin{array}{c}T=25^{\circ} \mathrm{C}, \\
P=1 \text { bar }\end{array}$ & $\begin{array}{c}T=185^{\circ} \mathrm{C}, \\
P=150 \text { bar }\end{array}$ \\
\hline $\mathrm{H}_{2} \mathrm{O}$ & $\mathrm{H}_{2} \mathrm{O}$ & 2.4 & -- \\
\hline $1 \mathrm{M} \mathrm{CO}_{2}+\mathrm{H}_{2} \mathrm{O}$ & $\mathrm{H}_{2} \mathrm{O}$ & 2.5 & -- \\
\hline & $\mathrm{CO}_{2}$ & 3.2 & -- \\
\hline $1 \mathrm{M} \mathrm{NaCl}+1 \mathrm{M} \mathrm{CO}_{2}+\mathrm{H}_{2} \mathrm{O}$ & $\mathrm{H}_{2} \mathrm{O}$ & 0.9 & 12.9 \\
\hline & $\mathrm{CO}_{2}$ & 1.3 & 2.7 \\
\hline & $\mathrm{Na}$ & $\mathbf{0 . 6}$ & 3.0 \\
\hline & $\mathrm{Cl}$ & $\mathbf{0 . 9}$ & 1.5 \\
\hline
\end{tabular}

implications for olivine/passivating layer surface complexation and $\mathrm{Mg}$ dissolution kinetics. We plan to expand and refine these studies in the second year of our project, with special emphasis on establishing rigorous trends in solution kinetics with respect to solute concentration, pressure and temperature.

\section{CONCLUSIONS}

The species and their activities in the aqueous mineral carbonation solution can dramatically impact carbonation reactivity. Varying the alkali cation species present and their ratio resulted in the extent of carbonation varying by a factor of more than 20 from the least to the most effective alkali cation combination. The most promising solutions for enhancing carbonation discovered to date have nearly doubled the extent of carbonation observed using the previous optimum solution. High concentrations of $\mathrm{NaHCO}_{3}(2.5 \mathrm{M})$ and $\mathrm{KHCO}_{3}(5.5 \mathrm{M})$ were found to be particularly effective at enhancing carbonation. Although, the alkali chloride solutions studied to date exhibit poor carbonation reactivity, they can substantially enhance carbonation reactivity in combination with alkali bicarbonate under select conditions. $\mathrm{CO}_{2}(\mathrm{aq})$ and $\mathrm{HCO}_{3}{ }^{-}$ exhibit quite poor carbonation reactivity separately; however, together they play key synergistic roles, substantially enhancing carbonation.

Multi-phase fluid modeling offers the potential to significantly enhance carbonation by controlling the slurry-flow parameters that impact exfoliation and carbonation (e.g., via particleparticle and particle-wall collisions). A newly developed microscopic wall roughness model indicates wall roughness may significantly enhance exfoliation and carbonation, by enhancing cross-stream particle transport and particle collisions. The Fluent code was validated for application to multiphase flows to assess the complex effects governing flow. Initial application has been made to components of the ARC Flow-Loop reactor. Initial results reveal the radial distribution of flow and the cross-stream olivine particle velocity vectors in a component pipe section can be a strong function of particle mass/size distribution and mixing history, parameters that may be able to be used to enhance carbonation. A new mixing design is being explored. Initial experimental results demonstrate that the flow dynamics and particle mass/size distribution present can substantially impact exfoliation/carbonation. 
A controlled pressure (1 to $200 \mathrm{~atm})$ and temperature $\left(20\right.$ to $\left.250{ }^{\circ} \mathrm{C}\right) 20 \mathrm{kHz} 1500$ watt sonication system was successfully developed for these studies. The system is fully operational over the complete range of carbonation reaction conditions of interest. Initial studies of the effects of sonication temperature, pressure and time at full power have not yet been effective at enhancing carbonation. These studies will be completed in Year 2, together with investigations of the effect of fluid composition, and reactant particle concentration and size. During Year 2 those parameters that have been found to be individually effective at cost-effectively enhancing carbonation reactivity (e.g., controlled fluid flow conditions and aqueous chemistry) will be combined to explore the potential to synergistically stimulate exfoliation and enhance carbonation.

Incongruent dissolution generally results in silica-rich passivating layer (PL) formation, with silica dissolution-precipitation likely further contributing to PL growth. Observations of magnesite nanocrystals within the passivating layers that form indicate the layers exhibit significant permeability to the key reactants present (e.g., $\mathrm{Mg}^{2+}, \mathrm{H}^{+}, \mathrm{H}_{2} \mathrm{O}, \mathrm{CO}_{2}$, and $\mathrm{HCO}_{3}{ }^{-}$). The extent of carbonation is observed to increase dramatically with increasing weight $\%$ solids in stirred experiments, indicating particle-particle collisions are critical in enhancing exfoliation and carbonation. Addition of abrasive materials, such as quartz, can significantly enhance olivine carbonation, in further support of the importance of particle-particle collisions in exfoliation and carbonation processes. Multi-phase hydrodynamic calculations indicate secondary collisions can account for a large fraction of the abrasion/exfoliation observed. Large-scale atomic-level simulations of the reaction zone suggest that the PL possesses a "glassy" but highly defective $\mathrm{SiO}_{2}$ structure that can permit the diffusion of key reactants. Studies in Year 2 will emphasize the impact that controlled aqueous speciation, activity and slurry-flow dynamics have on the mechanisms that control carbonation reactivity, as they appear to offer the greatest potential to substantially reduce olivine mineral sequestration process cost. 


\section{REFERENCES}

1) Carbon Sequestration Research and Development, Offices of Science and Fossil Energy, U.S. Department of Energy (December 1999), and references therein.

2) Seifritz, W. Nature 345, 486 (1990).

3) Lackner, K.; Wendt, C.; Butt, D.; Joyce Jr., E.; Sharp, D.; Energy 20, 1153-70 (1995).

4) O'Connor, W., et al. Proc. $25^{\text {th }}$ Int. Tech. Conf. Coal Util. \& Fuel Syst. pp. 153-64 (2000).

5) O'Connor, W.K., et al. Proc. $27^{\text {th }}$ Int. Tech. Conf. Coal Util. \& Fuel Syst. pp. 819-30 (2002).

6) Novel Approaches to Carbon Management (National Academies Press, Wash. D.C., 2003)

7) O’Connor, W.K.; Walters, R.P.; Dahlin, D.C.; Rush, G.E.; Nilsen, D.N.; Turner, P.C.; Proc. 26th International Technical Conference on Coal Utilization \& Fuel Systems 2001, 765.

8) O’Connor, W.K.; Dahlin, D.C.; Rush, G.E.; Gerdemann, S.J.; Penner, L.R. Proc. 29th International Technical Conference on Coal Utilization \& Fuel Systems 2004, 71.

9) Yu, S.C.; Proc. Nat. Sci. Counc. A. ROC, 1997, 21, 173.

10) Ottonello, G.; Princivalle, F.; Della Giusta, A.; Phys. Chem. Miner. 1990, 17, 301.

11) Sommerfeld, M., 2003, "Analysis of collision effects for turbulent gas-particle flow in a horizontal channel: Part I. Particle transport", Int. Journal of Multiphase Flow, Vol. 29, pp. 675-699.

12) Sommerfeld, M., and Huber, N., 1999, "Experimental analysis and modelling of particlewall collisions", Int. Journal of Multiphase Flow, Vol. 25, pp. 1457-1489.

13) Patankar, S. V., "Numerical Heat Transfer and Fluid Flow", McGraw-Hill Book Company, 1980.

14) Lockhart R. W. and Martinelli R. C., "Proposed correlation of data for isothermal twophase, two-component flow in pipes", Chemical Engineering Progress, 45(1), pp. 39-48, 1949.

15) Béarat, H.; McKelvy, M.; Chizmeshya, A.V.G.; Gormley, D.; Nunez, R.; Carpenter, R.W.; Squires, K. Environmental Science and technology (submitted).

16) Hurlbut, Cornelius, S.; Klein, Cornelis; Manual of Mineralogy, $19^{\text {th }}$ Edition (John Wiley \& Sons, New York, 1977).

17) Potapov, V.V.; Glass Physics and Chemistry 2004, 30 (1), 82.

18) Weissbart, E.J.; Rimstidt, J.D.; Geochim. Cosmochim. Acta 2000, 64 (23), 4007.

19) Johnson, C.L.; Hytch, M.J.; Buseck, P.R.; Amer. Mineral. 2004, 89, 1374; Wenk, H. Ed. Electron Microscopy in Mineralogy (Springer-Verlag, Berlin, 1976), Chapters 6.1 and 6.6.

20) Luce, R.W.; Bartlett, R.W.; Parks, G.A.; Geochim. Cosmichim. Acta 1972, 36, 35.

21) Wogelius, R.A.; Walther, J.V.; Geochim. Cosmichim. Acta 1991, 55, 943.

22) Jonckbloedt, R.C.L.; J, Geochem. Explor. 1998, 62, 337.

23) Chen, Y.; Brantley, S.L.; Chem. Geol. 2000, 165, 267.

24) Wolf, G.H.; Chizmeshya, A.V.G.; Diefenbacher, J.; McKelvy, M. J.; Environ. Sci. Technol. 2004, 38, 936.

25) Refson, K.; Moldy User's Manual, Rev. 2.25.2.6, release 2.16 (2001).

26) Matsui, M.; Phys. Chem. Min. 1988, 16, 234.

27) Birch, F.; J. Geophys. Res. 1978, 83, 1257.

28) Knittle, E.; Mineral Physics and Crystallography: A Handbook of Physical Constants, Ed. T.J. Ahrens, American Geophysical Union, 1995, 2, 98.

29) Johnson, P.A.V.; et al., J. Non-Crys. Solids 1983, 58, 109. 
30) Chizmeshya, A.V.G.; McKelvy, M.J.; Gormley, D.; Nunez, R.; Kim, Y.; Carpenter, R. Proc. 29th International Technical Conference on Coal Utilization \& Fuel Systems 2004, 1, 59.

31) Cerius2 Simulation Program, Accelrys Inc., San Diego, California (2003).

32) Franks, F; Water: A matrix of life, 2nd ed. (Royal Society of Chemistry, Cambridge, 2000).

33) Cate, A.T. ; Derksen J.J.; Portela, L.M.; van den Akker, H.E.A.; J. Fluid Mech. 2004, 519, 233.

34) Kim, M.G.; Dahman, U.; Searcy, A.W. J. Amer. Ceram. Soc.70, 146 (1987).

35) J. E. Hilliard, Trans. Met. Soc. AIME224, 906-917(1962).

36) J. M. Crompton, Brit. J. Appl. Appl. Phys.17, 1301-1305(1966).

37) T. Malis, S. Chung, and R.F. Egerton, J. Elec. Micros. Tech.8, 193(1988).

38) J. R. Smyth and T. C. McCormick, Crystallographic Data for Minerals, in A Handbook of Physical Constants: Mineral Physics \& Crystallography (Vol. 2), ed. T. J. Ahrens, American Geophysical Union(1995).

39) W. D. Kingery et al, Introduction to Ceramics, $2^{\text {nd }} E d$., John Wiley and Sons(1976)

40) G. C. Stoney, Proc. Roy. Soc. London A82, 172 (1909).

41) E. Suhir, J. Appl. Mech. 53, 657-660(1986)

42) Sun, H. (1998). COMPASS: An ab Initio Force-Field Optimized for Condensed-Phase Applications-Overview with Details on Alkane and Benzene Compounds, J. Phys. Chem. B, 102, 7338-64.

43) "An improved model calculating $\mathrm{CO}_{2}$ solubility in pure water and aqueous $\mathrm{NaCl}$ solutions from 273 to $533 \mathrm{~K}$ and from 0 to 2000 bar", Z. Duan and R. Sun, Chemical Geology 193 (2003) 257-271.

44) "Pressure-Volume-Temperature Properties of $\mathrm{H}_{2} \mathrm{O}-\mathrm{CO}_{2}$ Fluids" T.S. Bowers, Rock Physics and Phase Relations: Handbook of Physical Constants AGU Reference Shelf 3, 1995.

45) "Concentration Effects in Aqueous $\mathrm{NaCl}$ Solutions. A Molecular Dynamics Simulation", A.P. Lyubartsev and A. Laaksonen, J. Phys. Chem. 1996, 100, 16410-16418. 